\title{
High-affinity nitrate/nitrite transporter genes (Nrt2) in Tisochrysis lutea: identification and expression analyses reveal some interesting specificities of Haptophyta microalgae
}

\author{
Charrier Aurélie ${ }^{1}$, Bérard Jean-Baptiste ${ }^{1}$, Bougaran Gaël ${ }^{1}$, Carrier Grégory ${ }^{1}$, Lukomska Ewa ${ }^{1}$, \\ Schreiber Nathalie ${ }^{1}$, Fournier Flora ${ }^{1}$, Charrier Aurélie F. ${ }^{1}$, Rouxel Catherine ${ }^{1}$, Garnier Matthieu ${ }^{1}$, \\ Cadoret Jean-Paul ${ }^{1}$, Saint-Jean Bruno ${ }^{1,{ }^{*}}$ \\ ${ }^{1}$ IFREMER, Physiology and Biotechnology of Algae Laboratory, Nantes 44311, France \\ * Corresponding author : Bruno Saint-Jean, email address : bruno.saintjean@ifremer.fr
}

\begin{abstract}
:
Microalgae have a diversity of industrial applications such as feed, food ingredients, depuration processes and energy. However, microalgal production costs could be substantially improved by controlling nutrient intake. Accordingly, a better understanding of microalgal nitrogen metabolism is essential. Using in silico analysis from transcriptomic data concerning the microalgae Tisochrysis lutea, four genes encoding putative high-affinity nitrate/nitrite transporters (TINrt2) were identified. Unlike most of the land plants and microalgae, cloning of genomic sequences and their alignment with complementary DNA (cDNA) sequences did not reveal the presence of introns in all TINrt2 genes. The deduced TINRT2 protein sequences showed similarities to NRT2 proteins of other phyla such as land plants and green algae. However, some interesting specificities only known among Haptophyta were also revealed, especially an additional sequence of 100 amino acids forming an atypical extracellular loop located between transmembrane domains 9 and 10 and the function of which remains to be elucidated. Analyses of individual TINrt2 gene expression with different nitrogen sources and concentrations were performed. TINrt2.1 and TINrt2.3 were strongly induced by low NO3- concentration and repressed by NH4+ substrate and were classified as inducible genes. TINrt2.2 was characterized by a constitutive pattern whatever the substrate. Finally, TINrt2.4 displayed an atypical response that was not reported earlier in literature. Interestingly, expression of TINrt2.4 was rather related to internal nitrogen quota level than external nitrogen concentration. This first study on nitrogen metabolism of $T$. lutea opens avenues for future investigations on the function of these genes and their implication for industrial applications.
\end{abstract}


Abbreviations

AA

amino acids

AN

ammonium nitrate

cDNA

CHATS

complementary DNA

cLATS

constitutive high-affinity transport system

CT

constitutive low-affinity transport system

threshold cycle

GAPDH

glyceraldehyde 3-phosphate dehydrogenase

GS/GOGAT

HATS

glutamine synthetase/glutamine oxoglutatate aminotransferase

iHATS

high-affinity transport system

inducible high-affinity transport system

iLATS

inducible low-affinity transport system

LATS

low-affinity transport system

MFS

mRNA

major facilitator superfamily

messenger RNA

NAR

nitrite transporter

$\mathrm{NiR}$

nitrite reductase

NNP

nitrate/nitrite porter

NR

nitrate reductase

NRT

nitrate transporter

PTR

peptide transporter

Q-RT-PCR

quantitative real-time polymerase chain reaction 


\section{Introduction}

Nitrogen is an essential element for all living organisms. It participates in many crucial biological processes, including the formation of amino acids, proteins and chlorophyll. Nitrogen is preferentially absorbed in the ammonium form, however this form is scarce in the environment and nitrate is the most commonly used source of nitrogen (Forde, 2000).

Many reports have described the nitrate assimilation pathway in higher plants and certain microalgae (Crawford and Forde, 2002; Fernandez and Galvan, 2008, 2008; Ullrich, 1983). The first step of nitrate assimilation involves nitrate uptake across the plasma membrane by different types of nitrate transporters (NRT) and seems to be a major step in controlling nitrogen assimilation (Daniel-Vedele et al., 1998; Fernandez and Galvan, 2008). In cells, nitrate is reduced to nitrite in the cytoplasm by nitrate reductase (NR). Nitrite is transported into the chloroplast by a nitrite transporter (NAR1) for its reduction to ammonia by nitrite reductase (NiR). Ammonia is then incorporated into carbon skeletons by the glutamate dehydrogenase or the combined action of glutamine synthetase and glutamate synthase (Ahmad and Hellebust, 1984). In plants, nitrate can also be stored in vacuoles by the action of nitrate antiporters and nitrate transporters located on the tonoplast (De Angeli et al., 2006; Dechorgnat et al., 2012). In green microalgae, different storage structures (contractile vacuoles, intracellular granules) have been described but their origins and their functions remain unclear (Becker, 2007). Studies have shown that the transport capacities of the tonoplast membranes in green algae are similar to those of land plants (Becker, 2007) However, no nitrate transporters have yet been located on intracellular organelles of microalgae. Moreover, although many processes in nitrate assimilation are common to both algae and higher plants, Ullrich (1983) suggested that some differences could exist due to differential evolution, differences in the structural properties of the enzymes among these species and, most importantly, the large surface area of contact that algal cells have with external nutrients.

In recent years, the mechanisms that respond to nitrate availability have been the subject of much research. Previous studies indicate that $\mathrm{NO}_{3}{ }^{-}$uptake requires an active transport system (Forde, 2000; Galvan and Fernández, 2001). Molecular investigations in land plants have shown that four types of transport systems exist depending on the concentration of nitrate in the environment (Crawford and Glass, 1998). Two high-affinity transport systems (HATS) co-exist and can take-up $\mathrm{NO}_{3}{ }^{-}$at very low external concentrations $(<250 \mu \mathrm{M})$. The first system (iHATS) is inducible by $\mathrm{NO}_{3}{ }^{-}$and characterized by high values of $K_{m}$ and $V_{\text {max }}$ (for plants, typically 20-100 $\mu \mathrm{M}$ and 3-8 $\mu$ mol.g.h ${ }^{-1}$, respectively). The second system (cHATS) is constitutively expressed and does not depend on the nitrogen concentration, having low values of both $\mathrm{K}_{\mathrm{m}}$ and $\mathrm{V}_{\max }$ (for plants 6-20 $\mu \mathrm{M}$ and 0.3-0.82 $\mu \mathrm{mol.g.h}{ }^{-1}$, respectively) (Crawford and Glass, 1998). When the $\mathrm{NO}_{3}{ }^{-}$external concentration reaches values 
around the $500 \mu \mathrm{M}$ range, two other transport systems with low-affinity for nitrate (cLATS and iLATS) become involved in the absorption flux (Crawford and Glass, 1998; Galvan and Fernández, 2001; Glass et al., 1992; Siddiqi et al., 1990). The low-affinity transport system is unsaturable.

The Peptide Transporter (PTR) and the Nitrate/Nitrite Porter (NNP) gene families, belonging to the Major Facilitator Superfamily (MFS), have been identified as encoding putative nitrate transporters (Forde, 2000; Tsay et al., 2007). The MFS proteins have a typical membrane topology of 12 transmembrane domains arranged as two sets of six, connected by a cytosolic loop (Forde, 2000; Galvan and Fernández, 2001). The amino acid sequences share a conserved sequence motif [G-X-D$\left.\mathrm{X}_{2}-\mathrm{G}-\mathrm{X}-\mathrm{R}\right]$ between transmembrane domains 2 and 3 , and another motif [I- $\mathrm{X}_{2}-\mathrm{R}-\mathrm{X}_{3}-\mathrm{G}-\mathrm{X}_{3}-\mathrm{G}$ ] within transmembrane domain 4. The PTR family is a multigenic family found in a wide variety of plants and algae (Steiner et al., 1995). It includes several members characterized as low affinity nitrate transporters (Npf genes formely named Nrt1 genes) (Crawford and Glass, 1998; Forde, 2000; Léran et al., 2014). One exception is observed for Nrt1.1, which possesses a double affinity for $\mathrm{NO}_{3}^{-}$(HATS / LATS) (Liu et al., 1999; Wang et al., 1998). The NNP family includes high-affinity nitrate/nitrite transporters (Nrt2 genes). The NRT2 proteins have between 500-600 AA and present a consensus motif [FYK]-X ${ }_{3}$-[ILQRK]-X-[GA]-X-[VASK]-X-[GASN]-[LIVFQ]-X ${ }_{1,2}-\mathrm{G}-\mathrm{X}-\mathrm{G}-[\mathrm{NIM}]-\mathrm{X}-\mathrm{G}-[\mathrm{GTA}]$ within the fifth putative transmembrane domain. This motif is proposed as the signature for the NNP family (Forde, 2000). A portion of this sequence [A-G-W/L-G-N-M-G] has been also suggested as the substrate recognition motif. The members of the Nrt2 gene family show substrate specificity for nitrate and/or nitrite with different affinities. The first member of the NNP family to be cloned was the CrnA gene from Aspergillus nidulans (Brownlee and Arst, 1983; Unkles et al., 1991) and was identified to be a functional nitrate/nitrite transporter when expressed in Xenopus oocytes (Zhou et al, 2000). Then, Nrt2 genes from Chlamydomonas reinhardtii were identified to mediate high affinity nitrate transport like CrnaA gene. After, many studies identified Nrt2 genes in different species of land plants and microalgae (e.g. Arabidopsis thaliana, Nicotiana tabacum, Oryza sativa and Dunaliella salina) based on the sequence homology analysis (Cai et al., 2008; He et al., 2004; Krapp et al., 1998; Orsel et al., 2002). The number of high-affinity nitrate/nitrate transporters varies between species. Recent studies on the green microalga $C$. reinhardtii have provided information on the properties of NRT2 (Fernandez and Galvan, 2007; Galván et al., 1996; Quesada et al., 1994, 1998). In fact, C. reinhardtii have four $\mathrm{NO}_{3}{ }^{-}$or/and $\mathrm{NO}_{2}{ }^{-}$uptake systems, each with distinctive kinetic and regulatory properties, and some of these systems require the presence of an accessory protein (NAR2) to be functional (Galván et al., 1996; Rexach et al., 1999, 2002). Thereafter, other NAR2 proteins have since been identified in land plants (Orsel et al., 2006; Tong et al., 2005).

The high-affinity nitrate transporters in marine microalgae are of particular interest due to the low nitrate concentrations available in seawater (Collos et al., 2005; Song and Ward, 2007). Research has 
been conducted on marine microalgae for many years for the economic development of its biomass and various molecules that have high added value such as antioxidants, pigments and polysaccharides. However, microalgae have significant nitrogen needs to develop and produce their biomass. In the future, the price of nitrogen fertilizer will tend to increase in relation to the price of energy. Therefore, it is important to improve our knowledge of nitrogen absorption and assimilation mechanisms in these species. Haptophyta represent a major phylum of marine eukaryotic phytoplankton, ecologically dominant in ocean euphotic zones. A culture strain originally isolated from Tahiti and named Tisochrysis lutea (formerly Isochrysis affinis galbana) has been extensively studied due to its widespread use in aquaculture as feed for shellfish and shrimps (Bougaran et al., 2003; Bendif et al. 2013). T. lutea remains very difficult to transform and genetic tools suitable for the study of the regulation of the N-metabolism pathway in this taxon are scarce. The present study used integrative physiological and molecular approaches to improve our understanding of nitrogen metabolism in $T$. lutea. In this paper, we present the first molecular characterization of individual genes encoding putative high-affinity nitrate/nitrite transporters (Nrt2) in the Haptophyta. Using transcriptomic data, we identified four Nrt2 genes in T. lutea. Analyses of the Tisochrysis NRT2 sequences reveal some interesting specificities compared with NRT2 proteins of other phyla such as land plants and green algae. Moreover, several experimental investigations revealed gene expression profiles similar to land plants for three genes in $T$. lutea and, unexpectedly, one gene that presents a very atypical expression profile, never observed in any other phylum.

\section{Material and Methods}

\section{Strain and strain maintenance}

Wild-type Tisochrysis lutea was provided by the Culture Centre of Algae and Protozoa (CCAP 926/14). An axenic T. lutea strain was grown in a Conway medium (Walne, 1966) prepared with seawater, in a controlled environment with a constant irradiance of $150 \mu \mathrm{mol} \cdot \mathrm{m}^{-2} \cdot \mathrm{s}^{-1}$ at $22^{\circ} \mathrm{C}$. Population densities were estimated by cell counting and by spectrophotometry measuring the $\mathrm{OD}_{680}$ and $\mathrm{OD}_{800}$.

\section{Elementary analyses}

Particulate Nitrogen $(N)$ and Carbon $(C)$ concentrations $(\mu M)$ were estimated by filtering given volumes of cells on precombusted $25 \mathrm{~mm}$ GF/C filters (Whatman, $1.2 \mu \mathrm{m}$ ). The filters were then dried for $24 \mathrm{~h}$ at $70^{\circ} \mathrm{C}$ and further analysed using a CN Elemental Analyzer (Flash 2000, Thermoscientific). Particulate N/C ratios were calculated by dividing the particulate $\mathrm{N}$ concentration by the particulate $\mathrm{C}$ concentration. 


\section{Residual Nitrogen analysis}

Residual $\mathrm{NO}_{3}, \mathrm{NO}_{2}$ and $\mathrm{NH}_{4}$ concentration in $1.2 \mu \mathrm{m}$ filtrates was measured using an AA3 $\mathrm{HR}$ autoanalyser (Serlabo technologies) according to an automated spectrophotometric method (Aminot and Kérouel, 2007).

\section{Identification and cloning of nitrate/nitrite transporter genes in Tisochrysis lutea}

Transcriptomic data (Carrier et al., 2014) were used to identify nitrate/nitrite transporter genes in $T$. lutea. The gene-specific primers were designed for each TlNrt2 gene and used for PCR amplification (see Appendix S1 in Supporting Information). The amplified products were examined on agarose gels by electrophoresis and were purified using QIAquick PCR Purification Kit (Qiagen) following the manufacturer's instructions. The clean PCR products were cloned using a TOPO TA Cloning Kit (Invitrogen) and the ligated plasmids were transformed into Escherichia coli (One Shot ${ }^{\circledR}$ TOP10 Chemically Competent E. coli). The transformed cells were spread on Luria-Bertani medium containing $50 \mu \mathrm{g} . \mathrm{mL}^{-1}$ kanamycin with agar on plates. The full-length cDNA were re-sequenced using the SANGER method by GATC Biotech (Germany).

\section{Sequence analyses}

Several programs were used to analyse the T. lutea NRT2 sequences. The prediction of transmembrane domains was performed with TMPred software (Hofmann, 1993). WolfPsort was used to predict the subcellular localization of the proteins (Horton et al., 2007) and iPsort software was used as the subcellular localization site predictor for $\mathrm{N}$-terminal sorting signals (signal peptide, mitochondrial targeting peptide, or chloroplast transit peptide) (Bannai et al., 2002). The NetphosK program was used to predict putative kinase phosphorylation sites in the amino acid sequences (Blom et al., 1999). The sequence alignments were performed with ClustalW or MUSCLE software. The homology analyses were performed by using the BLAST program on the NCBI database and T. lutea transcriptome.

\section{Homology trees of NRT2 proteins}

Reference amino acid sequences were obtained from the GenBank database: Arabidopsis thaliana (NP_190092 ; AEE28241), Brassica napus (CAC05338), Glycine max (NP_001236444), Nicotiana plumbaginifolia (CAA69387), Oryza sativa (BAA33382), Solanum lycopersicum (NP_001234127), Triticum aestivum (AAK19519), Zea mays (NP_001105780), Chlorella sorokiniana (AAK02066), Chlorella variabilis (EFN52690), Cylindrotheca fusiformis (AAD49572), Dunaliella salina (AAU87579), Dunaliella_tertiolecta (ABP01763), Chlamydomonas reinhardtii (CAD60538 ; CAA80925), Emiliania huxleyi CCMP1516 (EOD39011), Emiliania huxleyi (ABP01765), Tetraselmis chui (ADU76799), Thalassiosira pseudonana (ACI64621), Ostreococcus tauri (XP_003091529), Skeletonema costatum (AAL85928), Volvox carteri (EFJ43757), Aspergillus nidulans (AAA76713), 
Hebeloma cylindrosporum (CAB60009), Neurospora crassa (CAD71077), Hansenula polymorpha (CAA11229), Agrobacterium sp. H13-3 (YP_004277958), Burkholderia rhizoxinica (YP_004022689), Pseudomonas stutzeri (WP_003298315), Calothrix sp. PCC 6303 (AFZ00090), Chroococcidiopsis thermalis PCC 7203 (YP_007092893), Cyanobacterium stanieri PCC 7202 (AFZ48362). The amino acid sequences were aligned using MUSCLE software and the resulting alignment file was used to construct a homology tree using PhyML software through the phylogeny.fr website (Dereeper et al., 2008). The homology tree was drawn with Treedyn software.

\section{Quantification of abundance transcripts by quantitative RT-PCR}

\section{RNA Extraction and Reverse Transcription}

The samples were centrifuged ( $20 \mathrm{~min}, 5000 \mathrm{~g}, 4^{\circ} \mathrm{C}$ ). The supernatant was discarded and the sea water was taken up to remove the salt. The pellets were resuspended in Trizol reagent (Invitrogen) and chloroform. After centrifugation, the upper phases were collected and 0.5 volume of absolute EtOH was added. The samples were transferred to a column of the RNeasy Plant mini kit (Qiagen) and the manufacturer's instructions followed thereafter. A DNase treatment (RQ1 DNase, Promega) was applied and total RNA purified using the RNeasy Plant Mini Kit with the RLT buffer and EtOH. The quality and concentration of RNA were determined with a spectrophotometer (ND-1000; NanoDrop Technologies, Wilmington, DE) at wavelengths of $260 \mathrm{~nm}$ and $280 \mathrm{~nm}$. The PCR amplification of an RNA sample served as a check for genomic DNA contamination. Total RNA was stored at $-80^{\circ} \mathrm{C}$. Reverse transcription of RNA was performed using the High Capacity cDNA Reverse Transcription kit (Applied Technologies) following the manufacturer's instructions.

\section{Real-Time PCR and SYBR Green Detection}

Quantitative PCR reactions were initiated by adding the cDNA to the SYBR Green PCR master mix (Applied Biosystems) and $300 \mathrm{nM}$ of forward and reverse primers. Ubiquitin and GAPDH genes were chosen as reference genes and remained stable in our experiments. These primer sets were specifically designed to amplify a 100- to 150-bp fragment from the genes TlUbi, TlGAPDH, TINrt2.1, TINrt2.2, TlNrt2.3 and TlNrt2.4 in T. lutea (see Appendix S2 in Supporting Information). The reactions were carried out on an Agilent Mx3000P QPCR System (Agilent technologies). PCR settings were $95^{\circ} \mathrm{C}$ for $10 \mathrm{~min}$ and then $95^{\circ} \mathrm{C}$ for $15 \mathrm{~s}$, and $60^{\circ} \mathrm{C}$ for $1 \mathrm{~min}$ for 40 cycles. The fluorescence intensity from the complex formed by SYBR Green and the double-stranded PCR product was continuously monitored from cycles 1 to 40 . The threshold cycle (CT) at which the fluorescence intensity became higher than a preset threshold was used to calculate the gene transcript level.

To obtain the gene expression data, the comparative CT method and standard curve method were combined to calculate an RNA molar ratio between a target gene and a reference gene, as previously described by Chung et al. (2005). Standard curves of each gene were generated to calibrate the PCR 
efficiency, and the slopes of standard curves were -3.2 (TIUbi mRNA), -3.4 (TIGAPDH mRNA), -3.2 (TlNrt2.1), -3.28 (TlNrt2.2), and -3.33 (TlNrt2.3) and -3.353 (TlNrt2.4) respectively. The relative mRNA abundance (X0/R0, in mmol of the target gene (mol TlUbi mRNA) ${ }^{-1}$ ), was calculated by the following equation: $\log \left(\mathrm{X}_{0} / \mathrm{R}_{0}\right)=\log \left(\mathrm{M}_{\mathrm{r}} / \mathrm{Mx}\right)+\left(\mathrm{Ct}_{\mathrm{x}} / \mathrm{b}_{\mathrm{x}}\right)-\left(\mathrm{Ct}_{\mathrm{r}} / \mathrm{b}_{\mathrm{r}}\right)$, where $\mathrm{X}_{0}$ and $\mathrm{R}_{0}$ are the initial numbers of target and reference molecules, $M_{r}$ and $M_{x}$ are the molecular weights of the target and reference amplicons, $\mathrm{Ct}_{\mathrm{x}}$ and $\mathrm{Ct}_{\mathrm{r}}$ are the threshold cycle numbers of $\mathrm{X}$ and $\mathrm{R}$, and $\mathrm{b}_{\mathrm{x}}$ and $\mathrm{b}_{\mathrm{r}}$ are the standard curve slopes of $\mathrm{X}$ and $\mathrm{R}$, respectively. The specificity of the quantitative reverse-transcription PCR (Q-RT-PCR) products was confirmed by melting temperature analysis.

\section{Experimental protocols}

Expression studies of Tisochrysis Nrt2 genes during batch culture with $\mathrm{NaNO}_{3}$

An axenic preculture of $T$. lutea was grown in a Conway medium with $1 \mathrm{mM} \mathrm{NaNO}$. During exponential phase, which corresponds to a high nitrogen quota, cells were inoculated into a new modified Conway medium containing $200 \mu \mathrm{M} \mathrm{NaNO}$. The initial cellular density in the new batch culture was about $2 * 10^{6}$ cells. $\mathrm{mL}^{-1}$. The irradiance and temperature were set at $200 \mu \mathrm{mol} . \mathrm{m}^{-2} . \mathrm{s}^{-1}$ and $22^{\circ} \mathrm{C}$ respectively. The cultures were aerated with $0.2-\mu \mathrm{m}$ filtered air and $\mathrm{pH}$ was adjusted to 8.0 with $\mathrm{CO}_{2}$ injections. Discrete sampling was realized and three parameters were monitored throughout the experiment: the nutritional status (particulate Nitrogen and Carbon), the composition of the medium (residual $\mathrm{NO}_{3}$ ) and the abundance of TINrt2 transcripts.

Expression studies of Tisochrysis Nrt2 genes during batch culture with $\mathrm{NH}_{4} \mathrm{Cl}$

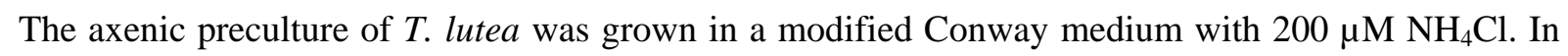
the stationary phase, corresponding to a low nitrogen quota, cells were inoculated into non-enriched seawater for 24 hours in order to lower the natural nitrogen content of the seawater. Then, a new modified Conway medium with $200 \mu \mathrm{M} \mathrm{NH} \mathrm{N}_{4} \mathrm{Cl}$ was added. The initial cellular density in the new batch culture was about $1.5^{*} 10^{6}$ cells. $\mathrm{mL}^{-1}$. The irradiance and temperature were fixed at $200 \mu \mathrm{mol} . \mathrm{m}^{-}$ ${ }^{2} . \mathrm{s}^{-1}$ and $22^{\circ} \mathrm{C}$, respectively. The cultures were aerated with $0.2-\mu \mathrm{m}$ filtered air and $\mathrm{pH}$ was adjusted to 8.0 with $\mathrm{CO}_{2}$ injections. A discrete sampling was performed and three parameters were monitored throughout the experiment: the nutritional status (particulate Nitrogen and Carbon), the composition of the medium (residual $\mathrm{NO}_{3}$ ) and the abundance of TlNrt2 transcripts.

Concerning the TlNrt2 relative mRNA abundance as a function of the $\mathrm{N} / \mathrm{C}$ ratio ( $\mathrm{N}$ status) in cells, $\mathrm{N} / \mathrm{C}$ ratios were calculated by dividing the particulate $\mathrm{N}$ concentration by the particulate $\mathrm{C}$ concentration.

Regulation of TINrt2 expression by different $N$-substrate conditions 
To study the short-term regulation of TINrt2 expression by $\mathrm{N}$ metabolites, $3 \mathrm{~L}$ of axenic cultures growing in continuous culture with N-limiting conditions were transferred into sterilized bottles. The cultures were aerated with $0.2-\mu \mathrm{m}$ filtered air and received a constant irradiance of $200 \mu \mathrm{mol} \mathrm{m} \mathrm{m}^{-2} \mathrm{~s}^{-1}$ and the $\mathrm{pH}$ was adjusted to 8.0 with $\mathrm{CO}_{2}$ injections. Cells were left without any nutritional supply for the time necessary to clear their internal nitrogen quotas. It was considered that the cells had the lowest nitrogen quotas when the algal growth was at stationary phase. Different types of Conway media were prepared from different forms of nutrients $\left(\mathrm{NaNO}_{3} ; \mathrm{NaNO}_{2}\right.$ and $\left.\left(\mathrm{NH}_{4}{ }^{+}\right)\left(\mathrm{NO}_{3}{ }^{-}\right)\right)$, but all containing $1 \mathrm{mM}$ of total nitrogen, and were added to the different cultures independently. Samples were collected and total RNA extractions were performed at 0, 15, 30, 60 and 120 min after $\mathrm{N}$ repletion. All experiments were performed in triplicate.

\section{Statistics}

Statistical analyses were performed with Matlab ${ }^{\circledR}$ (Mathworks, Natick, Massachusetts, United States) using Kruskal-Wallis test $(\alpha=0.05)$.

\section{Results}

\section{Identification of Tisochrysis lutea Nrt2 transcripts}

In this study, four genes, encoding putative high-affinity nitrate/nitrite transporters, have been identified in T. lutea based on our transcriptomic data (Carrier et al., 2014) and were named TINrt2.1, TlNrt2.2, TINrt2.3 and TlNrt2.4. The TlNrt2 gene identification was performed by similarity searches, using several NRT2 sequences from different species (Aspergillus nidulans, Hansenula polymorpha, Arabidopsis thaliana, Oryza sativa and Dunaliella salina), against the transcriptome database of $T$. lutea (Fig. 1). The respective TlNrt2 full-length cDNAs were cloned and re-sequenced to confirm sequence reliability.

In addition, T. lutea was checked for the presence of any NAR2 accessory protein. Nevertheless, despite numerous homology searches using various NAR2 sequences from several species [A. thaliana (AED95911.1), Cucumis savitus (ACV33078.2), Micromonas sp. RCC299 (ACO68771.1) and C. reinhardtii (A8J4P7)], no gene encoding a putative NAR2 protein was detected in T. lutea.

\section{Intron-Exon Structure of the Tisochrysis lutea Nrt2 genes}

Amplifications of genomic sequences were performed using primers designed in the 5'UTR and 3’UTR regions (see Appendix S1 in Supporting Information). The amplicons were sequenced using the SANGER method (GATC, Germany). To report the genomic and cDNA sequences of the TINrt2 genes, a full alignment of the cDNA sequences and the genomic sequences was performed using 
ClustalW software. No introns were detected in the genomic sequences using the alignments with the respective cDNA sequences.

Concerning the sequence comparison, the highest value of nucleotide sequence identity was found between TINrtT2.1 and TINrt2.3, with a value up to 82.8\% identity (See Appendix S3 in supporting information). However, strong identities were also observed between all of the TlNrt2 nucleotide sequences (from $68.4 \%$ to $79.1 \%$ ).

\section{Characteristics of deduced TINRT2 amino acid sequences obtained using bioinformatic tools} The deduced TINRT2.1, TINRT2.2, TINRT2.3 and TINRT2.4 proteins have 633, 630, 634 and 661 amino acid residues, respectively. These protein sequences showed strong similarities, with identity scores ranging up to 92.9 \% (See Appendix S3 in supporting information). The Wolf PSORT program (Horton et al., 2007) for prediction of protein subcellular localization placed the four T. lutea NRT2 on the plasma membrane. The iPSORT software (Bannai et al., 2002) did not detect the presence of any signal, mitochondrial targeting, or chloroplast transit peptides.

Hydropathic analysis was performed with the TMPred program and predicted the presence of 12 transmembrane domains. A first cytosolic loop was observed between transmembrane domains 6 and 7, and is specific to the MFS family. Contrary to the fungal and yeast NRT2 sequences, that have a large central cytosolic loop (90 AA), Tisochrysis NRT2 sequences show a short cytosolic loop (20-30 AA) as observed in land plants and green algae (Fig. 1). The specific domain (G- $\left.X_{3}-D-X_{2}-G-X-R\right)$ characteristic of the Major Facilitator Superfamily is identified between transmembrane domains 2 and 3 in T. lutea NRT2 sequences (Fig. 1). The signature motif for the Nitrate/Nitrite transPorters family (A-G-W/L-G-N-M-G), which is suggested as a recognition substrate motif, was also found in the fifth transmembrane domain.

A second loop is observed only in Tisochrysis NRT2 sequences and is located between transmembrane domains 9 and 10. This loop is extracellular and has about 100 AA, which is highly atypical compared with the NRT2 sequences from other species (Fig. 1). Homology researches were made on this atypical loop. The results of BLAST analysis showed that this additional sequence is not found in NRT2 sequences of other species, except in the NRT2 sequences of another haptophyte, E. huxleyi. Analysis of a shotgun proteomic experiment (not shown in this paper) confirmed the presence of these proteins and, more precisely, the additional amino acid sequence (see Appendix S5 in Supporting Information). Indeed, two peptides were identified in this additional loop of Tisochrysis NRT2 sequences. BLAST analyses then confirmed that these peptides did not match with other proteins from Tisochrysis lutea and were specific to TINRT2 proteins.

The deduced TINRT2 proteins show an extended N-terminal domain (30 AA) and an extended Cterminal domain as described in plants and green algae. However, the alignment in figure 1 shows that TINRT1, TINRT2.2 and TINRT2.3 sequences harbour C-terminal domains smaller (40 AA) than all others (60-70 AA). Using NetPhosK program (Blom et al., 1999), several protein kinase C recognition 
motifs are detected for only three TINRT2 sequences (TINRT2.1, TINRT2.2 and TINRT2.3), but at a different position to those found in other organisms. In contrast, no protein kinase $\mathrm{C}$ recognition motif was detected in TINRT2.4. Furthermore, the conserved protein kinase $C$ recognition motifs in land plants and green algae are not found for all TINRT2 proteins excepted for TINRT2.1, which harbours this motif type in the C-terminal domain (Fig. 1). Nevertheless, the same motif of phosphorylation by protein kinase $C$ is predicted within the additional sequences in three TINRT2 proteins (TINRT2.1, TINRT2.2 and TINRT2.3). Contrary to the yeast and fungal NRT2 sequences, no protein kinase C recognition motifs were detected in the central cytosolic loop.

\section{Similarity scores and homology tree}

The amino acid sequences of TINRT2 have fairly low homologies with NRT2 proteins of other species (See Appendix S4 in supporting information). Indeed, the identity scores obtained with AsCrnA (Aspergillus nidulans) and HpYNT1 (Hansenula polymorpha) were only about 26\% and 23\% respectively. Nevertheless, the identity scores seem to be greater with sequences of land plants and algae. For example, between $28.5 \%$ and $34.3 \%$ identity and up to $47.2 \%$ similarity was found with AtNRT2.1 (A. thaliana). Moreover, it was also shown that the protein sequences of $T$. lutea NRT2 show up to $35 \%$ identities with other NRT2 of algae (between $31 \%$ and $35 \%$ identities with Chlamydomonas reinhardtii NRT2.3).

In the same way, the homology tree highlights the fact that the Nrt2 genes from this haptophyte cluster with the Nrt2 genes from land plants and green algae (Fig. 2). This group, containing the Nrt2 genes of land plants, green algae and haptophytes, differs completely from other phyla (diatoms, fungi, cyanobacteria and bacteria). However, inside this group, results showed that the Nrt2 genes of green algae are closely related to the Nrt2 genes of land plants, while the Nrt2 genes of the Haptophyta are distinct to the green lineage. In addition, T. lutea Nrt2 seems to form a single clade, separate from those of E. huxleyi.

\section{Transcriptional responses of TINrt2 genes during nitrate batch culture}

In order to observe the expression of individual TlNrt2 genes during batch culture, cells with high nitrogen quotas (i.e. at the exponential phase) were inoculated in a modified Conway medium containing $200 \mu \mathrm{M}$ nitrate as the sole source of nitrogen. Cell density exponentially increased for 2 days before reaching the stationary phase (Fig. 3A). Residual nitrate provided at $200 \mu \mathrm{M}$ at day 0 was almost exhausted after $16 \mathrm{~h}$, and totally depleted from $22 \mathrm{~h}$ until day 4 . The transcript level of the nitrate transporter genes was monitored throughout the batch culture. The relative mRNA abundance was normalized using the reference gene (Ubiquitin).

The relative abundance of TlNrt2.1 transcripts showed an average of 17.2 mol.mol $^{-1}$ TlUbi mRNA when external nitrate was still abundant (Fig. 3B). Thereafter, the residual concentration of nitrate began to drop and an increase of the TINrt2.1 gene expression (24.1 mol.mol ${ }^{-1}$ TlUbi mRNA) was 
observed when the external nitrate concentration was around $30 \mu \mathrm{M}$. However, the TlNrt2.1 mRNA abundance expression peaked after the nitrate had been totally depleted from the medium (45.6 mol.mol ${ }^{-1}$ TlUbi mRNA, or 2.6-fold). This maximal transcript level of TlNrt2.1 remained stable until the cells reached the stationary phase.

The transcript level of TlNrt2.2 was relatively stable, with an average of $2.1 \mathrm{mmol}^{\mathrm{mol}}{ }^{-1} \mathrm{TlUbi} \mathrm{mRNA}$ throughout the experimental period (Fig. 3C). The results suggested that TINrt2.2 was constitutively expressed in these culture conditions.

For TlNrt2.3 gene, the transcript level remained stable until $28 \mathrm{~h}$ with an average of $1857 \mathrm{mmol}^{\mathrm{mol}}{ }^{-1}$ TlUbi mRNA and declined at $40 \mathrm{~h}$ (1105 mmol.mol ${ }^{-1}$ TlUbi mRNA) when the residual nitrate was undetectable (Fig. 3D). The TlNrt2.3 transcript level then reached 853 mmol.mol ${ }^{-1}$ TlUbi mRNA by the end of the experiment.

In contrast to other TlNrt2 genes, TlNrt2.4 transcript level was high (185 mmol.mol ${ }^{-1}$ TlUbi mRNA) when the external nitrate concentration was $200 \mu \mathrm{M}$ (Fig. 3E). Its expression decreased during nitrate consumption by algal cells to an average of $82.2 \mathrm{mmol} \mathrm{mol}^{-1}$ TlUbi mRNA. When the nitrate was totally depleted of the medium after $22 \mathrm{~h}$, no gene expression was detected until the end of the experiment.

\section{Transcriptional responses of TINrt2 genes during ammonium batch culture}

To determine the expression profile of each TINrt2 gene when the nitrate in the medium is replaced by ammonium as the sole nitrogen source, cells were inoculated in non-enriched seawater for 24 hours in order to lower the natural nitrogen content of the seawater. In addition, to observe a strong repression of TlNrt2 genes in the presence of ammonium, it was necessary that their expressions were high at the beginning of the experiment. For this reason, prior to their inoculation, cells with empty nitrogen quotas were preconditioned under $\mathrm{N}$ starvation. Once the initial physiological conditions were met, a modified Conway medium with $200 \mu \mathrm{M} \mathrm{NH}{ }_{4} \mathrm{Cl}$ was added. The growth pattern of the population showed that cell density increased exponentially for 3.8 days and then entered the stationary phase (Fig. 4A). The ammonium supplied was totally depleted after $20 \mathrm{~h}$ (day 0.8) and remained undetectable until day 4.8. The transcript level of the nitrate transporter genes was monitored throughout the batch culture.

In the nitrogen-starved cultures of T. lutea, the relative transcript levels of TlNrt2.1 and TlNrt2.3 were high, with average values of $64.8 \mathrm{~mol}^{\mathrm{mol}}{ }^{-1} \mathrm{TlUbi}$ mRNA and $1808 \mathrm{mmol} . \mathrm{mol}^{-1}$ TlUbi mRNA, respectively (Fig. 4B and 4D).

When $\mathrm{NH}_{4}{ }^{+}$was added to the $\mathrm{N}$-starved cultures, the relative transcript levels of TlNrt2.1 drastically declined to 80.5 mmol.mol ${ }^{-1}$ TlUbi mRNA (700-fold) observed $7 \mathrm{~h}$ after the addition of the $\mathrm{NH}_{4}{ }^{+}$(Fig. 4B). Thereafter, a very strong induction to an average value of $4473 \mathrm{mmol}^{\mathrm{mol}}{ }^{-1} \mathrm{TlUbi}$ mRNA was observed when the ammonium was totally depleted. The increase of relative transcript abundance continued until the end of the experiment (46 500 mmol.mol ${ }^{-1}$ TlUbi mRNA) in the N-starved cells. 
For TlNrt2.3 expression, the relative transcript abundance declined very quickly 328-fold (5.5 mmol.mol ${ }^{-1}$ TlUbi mRNA) in $4 \mathrm{~h}$ after the addition of $\mathrm{NH}_{4}{ }^{+}$(Fig. 4D). Thereafter, the transcript level increased when the external ammonium was completely depleted (309.9 mmol.mol ${ }^{-1}$ TlUbi mRNA). The increase of relative transcript abundance continued until the end of the experiment (1526.6 mmol.mol ${ }^{-1}$ TIUbi mRNA in day 2) in the N-starved cells.

The TINrt2.2 gene transcript level was low and remained relatively constant at an average of 2.7 mmol.mol ${ }^{-1}$ TlUbi mRNA throughout the experiment (Fig. 4C).

Finally, the TINrt2.4 expression profile was very atypical. In the nitrogen-starved cultures of T. lutea, the transcript level was low, with an average value of 1.5 mmol.mol $^{-1}$ TlUbi mRNA (Fig. 4E). Following the addition of $\mathrm{NH}_{4}{ }^{+}$to the N-starved cultures, the TINrt2.4 transcript level significantly increased by 6.6-fold after $4 \mathrm{~h}$ (10 mmol.mol ${ }^{-1}$ TlUbi mRNA) and remained approximately stable until day 1. Thereafter, the transcript level of TINrt2.4 fell dramatically in day 2 in the N-starved cells with an average of $1.76 \mathrm{mmol}_{\mathrm{mol}}{ }^{-1} \mathrm{TlUbi}$ mRNA.

\section{Transcriptional responses of $\mathbf{T l N r t 2}$ genes according to $\mathrm{N} / \mathrm{C}$ cell ratio}

$\mathrm{N}$ and $\mathrm{C}$ cell quotas have been analysed during the sampling of the ammonium batch culture in order to determine the N/C cell ratio. Thus the transcriptional responses of TlNrt2 genes have been highlighted according to the $\mathrm{N}$ status of $T$. lutea cells (Fig. 5). In concordance with the results, three distinct expression profiles are observed as indicated in figures 5A, 5B and 5C respectively. TINrt2.1 and TlNrt2.3 inducible genes responded with a same pattern, which is uncorrelated to the N/C cell ratio. For instance at the highest N/C values the expression of these two genes is only dependent of the residual nitrogen concentration (Fig. 5A). This non-correlation to the N/C cell ratio is signed by a "loop" pattern on the graph. As expected, the expression of TINrt2.2 constitutive gene was independent of N/C ratios as the residual nitrogen depletion (Fig. 5B). On the other hand, the TINrt2.4 gene was expressed regardless to the presence of ammonium substrate (Fig. 5C). A high expression of TINrt2.4 gene was observed for both residual nitrogen levels when the cell quota was full. In contrast, its gene expression was strongly repressed for empty cell quota (5-fold). Moreover a significant threshold near to $\mathrm{N} / \mathrm{C}=0.11(\mathrm{P}<0.05 ; \mathrm{n}=21)$ was observed.

\section{Regulation of Tisochrysis lutea Nrt2 genes by nitrate and different reduced nitrogen sources.}

In our earlier experiment, we observed an expression of three TlNrt2 genes in N-starvation conditions (Figs. 3 and 4). In order to investigate the impact of high concentrations of different nitrogen sources (1 mM of total nitrogen) on TlNrt2 gene expression, a short-term incubation experiment (lasting two hours) using different sources of nitrogen was performed after N-starvation preconditioning.

Under nitrate-repletion, the mRNA abundance of TINrt2.1 decreased until reaching a value equal to 0.5-fold the value of the mRNA abundance observed under nitrogen-starvation (Fig. 6A). Interestingly, under nitrite repletion, the mRNA abundance of TINrt2.1 also decreased but quicker than 
under nitrate-repletion (0.2-fold at 2 hours). Finally, under ammonium nitrate-repletion, the expression of TlNrt2.1 gene was rapidly and strongly repressed after $30 \mathrm{~min}$.

After 2 hours under nitrate repletion, the mRNA abundance of TlNrt2.3 decreased very slightly to 0.7fold compared with the mRNA abundance under nitrogen-free conditions. The slight decrease of TlNrt2.3 gene was minor compared with the decrease in TlNrt2.1 mRNA abundance. However, results also show that the TlNrt2.3 expression profile was quite similar to that of TINrt2.1 in response to nitrite repletion and AN repletion (Fig. 6C). Indeed, after nitrite addition, the repression of the TlNrt2.3 gene was very strong compared with nitrogen-free conditions (0.1-fold). The minimal transcript level of TlNrt2.3 was observed $2 \mathrm{~h}$ after the addition of ammonium nitrate (no expression was observed after 2 hours).

The expression of TlNrt2.2 gene was relatively constant throughout the experiment and seemed to be the same whatever the conditions of $\mathrm{N}$ repletion (Fig. 6B). Therefore, results confirmed that TlNrt2.2 is constitutively expressed in these conditions.

Unexpectedly, the expression profile of TINrt2.4 gene under various $\mathrm{N}$-substrate conditions was completely different from the other TINrt2 genes (Fig. 6D). Indeed, under nitrate- and nitrite-repletion, the mRNA abundance of TlNrt2.4 decreased for at least 1 hour, with a ratio of 0.3 -fold and 0.2 -fold the level of mRNA observed under N-starvation conditions. Under AN repletion, results showed an induction of TlNrt2.4 expression compared with the initial conditions (5.6-fold). Interestingly, at 2 hours, a peak of TlNrt2.4 expression was observed whatever the nitrogen substrate, with ratios corresponding to 1.4-fold, 3-fold and 14-fold the mRNA abundance for the nitrate, nitrite and AN, respectively.

The addition of different nitrogen substrates involved in the nitrogen assimilation pathway allowed us to reveal the regulation kinetics of three TlNrt2 genes (TINrt2.1, TlNrt2.3 and TlNrt2.4) and the absence of TlNrt2.2 gene regulation in these conditions.

\section{Discussion}

To cope with the availability of nitrate in the environment, plants have transporters with different affinity for this substrate. A family of genes encoding high-affinity nitrate transporters (NRT2) is involved in nitrate uptake when the external nitrate concentrations are very low $(\mu \mathrm{M})$. In recent years, several Nrt2 genes have been identified in some land plants (Cai et al., 2008; Krapp et al., 1998; Orsel et al., 2002) and microalgae (He et al., 2004; Koltermann et al., 2003; Quesada et al., 1994). For instance, in the green algae $C$. reinhardtii, four members of the $N r t 2$ gene family were identified (Galvan \& Fernandez 2001). More recently, in the diatom Thalassiosira pseudonana, three putative nitrate transporter genes were reported (Song and Ward, 2007). However, most studies in microalgae only describe the global expression profile of the Nrt2 gene family and not the individual Nrt2 gene expression (Hildebrand and Dahlin, 2000; Kang et al., 2007; Song and Ward, 2007). Among these reports, only two studies have investigated the Haptophyta phylum. In this paper, we describe for the 
first time the individual Nrt2 gene expression pattern under specific physiological conditions in the haptophyte T. lutea.

\section{In silico analyses reveal four genes encoding putative high-affinity nitrate transporters (TINrt2) with original characteristics.}

We identified four genes encoding putative high-affinity nitrate transporters in the marine microalgae T. lutea. The identification was performed from transcriptomic data (Carrier et al., 2014) using homology searches with NRT2 of other species. Interestingly, cloning of genomic sequences and their alignment with the cDNA sequences did not reveal the presence of introns in putative TlNrt2 genes. Although the presence of introns in Nrt2 genes appears to be very variable, the presence of at least two introns have been described in dicotyledonous plants and some microalgae (Bhadury et al., 2011; Orsel et al., 2002; Plett et al., 2010), whereas no intron was detected in grasses plants (Plett et al., 2010). In microalgae particularly, Song and Ward (2007) characterized Nrt2 genes from several marine species and especially detected four introns in Nrt2 gene sequence of another haptophyte $E$. huxleyi. Nevertheless, Bhadury et al. (2011) suggest that there are large variations in intron number and length in phytoplankton genomes.

In silico analyses showed that the four TINRT2 deduced amino acid sequences are very similar to one another (95.7\% similarity), but have fairly low similarities with NRT2 of other phyla (land plants, green algae, fungi and yeast) (See Appendix S4 in supporting information). This can be explained by the fact that these species are relatively distant in terms of evolution, which is supported by the homology tree (Fig. 2). The distances shown by the tree confirm that the Nrt2 genes from haptophytes cluster with the Nrt2 genes from land plants and green algae and differ completely from other phyla. Nevertheless, our results also reveal that the Haptophyta Nrt2 genes are distinct to the green lineage and form an independent group.

The full bioinformatic analyses reveal that the deduced TINRT2 amino acid sequences have all the features of High Affinity Nitrate Transporters described in literature (Forde, 2002): 1) the 12 membrane-spanning domains separated by a central cytosolic loop as described in Major Facilitator Superfamily members, 2) the MFS conserved domain and 3) the NRT2 conserved motif. These results confirm that the four putative TINRT2 belong to the MFS family and encode high-affinity nitrate transporter proteins. The alignment also reveals that the central cytosolic loop in TINRT2 proteins is reduced (20-30 AA), as in land plants and microalgae, whereas this loop is much extended in yeast and fungi (90 AA) (Fig. 1). Furthermore, TINRT2 proteins present an extended N-terminal domain (20-30 AA) and a large C-terminal domain (60-70 AA), as described in NRT2 from green lineage species (Forde, 2000; Quesada et al., 1994; Trueman et al., 1996). In fact, previous studies suggested that the cytosolic loop and the C-terminal domain may have a regulatory function (Due et al., 1995; 
Katagiri et al., 1992; Liu et al., 1995). Indeed, conserved protein kinase C recognition motifs (S/T-X$\mathrm{R} / \mathrm{K}$ ) are present in the $\mathrm{N}$ - and C-terminal domains of plant and microalgal NRT2 and in the central loop of the fungal NRT2 (Fig. 1). The existence of these motifs could indicate that phosphorylation and dephosphorylation reactions play a part in the regulation of the activity of the NRT2 proteins. However, the analyses reveal that these kinase $\mathrm{C}$ specific phosphorylation motifs were not present in TINRT2 sequences and the lack of these conserved phosphorylation sites in TINRT2 proteins could imply that high-affinity nitrate transporters in T. lutea are regulated differently.

Interestingly, the presence of an atypical sequence of 100 amino acids length in TINRT2 sequences reveals an original specificity of the Haptophyta. The BLAST analysis results of this additional part with the non-redundant protein sequences (NCBI) fitted only with NRT2 sequences of another haptophyte E. huxleyi (data not shown). This unusual sequence forms an extracellular loop located between transmembrane domains 9 and 10. Many hypotheses could be formulated about the function of this atypical loop, especially that this additional sequence could be implicated in substrate binding or have a sensor function. These hypotheses could be supported by the fact that Tisochrysis NRT2 transporters may not need any NAR2 accessory proteins to function correctly in nitrate uptake, unlike to the majority of NRT2 proteins from land plants and microalgae. Indeed, no genes encoding accessory proteins (NAR2) were identified in T. lutea, despite many searches. It seems, therefore, that these accessory proteins are absent, suggesting that the Tisochrysis NRT2 could be a "single component", as is the case in yeast and fungal species. This Haptophyta particularity will require further investigations to elucidate the effective role of this additional loop. To our knowledge, it is the first time that this feature has been described.

\section{Genes encoding high-affinity transporters present different expression levels}

In concordance with the literature, TINrt2 genes present different expression levels (Figs. 3 and 4). Indeed, high expression was detected for the TINrt2.1 gene, with a strong expression under Nstarvation but also under nitrate-sufficient conditions. The TINrt2.3 is also strongly expressed in these conditions. Unlike the two latter genes, TINrt2.4 gene was poorly expressed and did not reach the levels of expression of two other genes. The lowest expression level for TINrt2 genes was observed for TINrt2.2, which has a very low expression in all conditions tested (Figs. 3 and 4). This is in concordance with previous studies in plants and microalgae that described a specific role for each of the nitrate transporters of the same family (Galván et al., 1996; Orsel et al., 2002).

\section{Experiments using $\mathrm{NO}_{3}{ }^{-}$or $\mathrm{NH}_{4}{ }^{+}$as nitrogen sources reveal the presence of inducible and constitutive systems in Tisochrysis lutea.}

Previous studies reported the total mRNA abundance of Nrt2 genes in several microalgae species during batch cultures, but without distinguishing the Nrt2 genes individually (Kang et al., 2007; Song 
and Ward, 2007). In this study, we monitored, for the first time, the individual time-course of the expression of the four Nrt2 genes in T. lutea depending on $\mathrm{N}$ source and $\mathrm{N}$ availability (Figs. 3 and 4 ). During the nitrate batch experiment, the transcript level of TINrt2.1 increased when the residual nitrate reached $30 \mu \mathrm{M}$ and peaked when the nitrate became undetectable in the medium (Fig. 3B). These results showed that TINrt2.1 could be considered as inducible either by nitrate at low concentration or $\mathrm{N}$ starvation. This expression under $\mathrm{N}$ starvation can be considered as an adaptive strategy for facilitating the synthesis of NRT2 protein when nitrate is provided. Some microalgae have already demonstrated a high expression of Nrt2 genes under N starvation (Kang et al., 2007; Song and Ward, 2007). Moreover, this behaviour is also observed in other transporter families that are strongly expressed in the absence of their substrates (Chung et al., 2003; Li et al., 2006; Matsuda and Colman, 1995). Differently, the TlNrt2.3 expression was maximal at the beginning of the nitrate batch experiment, i.e. when the nitrate was sufficient in the medium (Fig. 3D). Later in this experiment, the mRNA abundance of TlNrt2.3 was slightly decreased, although remaining high, when the cells were in N-starvation conditions (Fig. 3D). These results show that TINrt2.3 expression was induced in Nstarved cells, but nitrate is required for its maximal expression. Although the expression pattern is not exactly the same, TlNrt2.1 and TlNrt2.3 genes belong to the inducible HATS system. In contrast to these observations, the abundance of TINrt2.2 gene transcripts was stable throughout the nitrate batch culture (Fig. 3C). This expression pattern suggests that TlNrt2.2 belongs to the constitutive HATS component of the NRT2 family. Indeed, previous studies have shown that three genes encoding Nrt2 in A. thaliana were characterized as constitutively expressed even under $\mathrm{NO}_{3}{ }^{-}$-starved conditions and the expression levels did not change substantially during $\mathrm{NO}_{3}{ }^{-}$exposure (Okamoto et al., 2003).

Many studies have found that ammonium addition can inhibit the expression of Nrt2 genes in plants and microalgae (He et al., 2004; Hildebrand and Dahlin, 2000; Koltermann et al., 2003; Krapp et al., 1998; Quesada et al., 1994; Vidmar et al., 2000). Therefore, to determine the ammonium-repressed transcript levels of TlNrt2 genes in Tisochrysis lutea, the mRNA abundances were monitored during ammonium batch culture. As expected, the transcript levels of TlNrt2.1 and TlNrt2.3 genes decreased dramatically in presence of ammonium (Figs. 4B and 4D) and showed that these genes are actively repressed by this substrate. Once the ammonium became undetectable, very high induction was detected for TlNrt2.1 and TlNrt2.3 genes, as previously observed under N starvation. These expression profiles during ammonium batch culture are in concordance with a previous report that described a reduction of the total Nrt2 mRNA abundance in the presence of ammonium, but also a strong increase when ammonium became undetectable in the medium in I. galbana (Kang et al., 2007). Considering the overall results, TINrt2.1 and TINrt2.3 genes present a typical inducibility by both nitrate and $\mathrm{N}$ starvation but also a down-regulation in the presence of ammonium.

TINrt2.2 expression remained stable during the ammonium batch culture (Fig. 4C), confirming that this gene belongs to the constitutive HATS system. Indeed, in C. reinhardtii, studies showed the 
existence of a nitrate transport system IV containing the CrNrt2.4 gene, which is constitutively expressed and not repressed in the presence of ammonium (Rexach et al., 1999).

Our results on the TlNrt2.4 gene expression profile from all of our experiments will be discussed in its own specific section below.

\section{TINrt2 gene expression is differentially regulated by $\mathbf{N}$ metabolites}

Many reviews have reported the regulation of Nrt2 gene expression by the accumulation of $\mathrm{N}$ metabolites in plant cells (Forde, 2000; Miller et al., 2008). So, a short-term experiment was performed by adding high concentrations of different metabolisable nitrogen sources $(1 \mathrm{mM})$ to the medium in order to generate intracellular $\mathrm{N}$-metabolite accumulation.

The results showed that TlNrt2.1 and TlNrt2.3 gene expression was down-regulated when nitrogen elements were provided at very high concentrations. A strong repression was observed after only 30 min of treatment with nitrate, nitrite and ammonium nitrate (Figs. 6A and 6C). This repression continued for 1 hour until reaching the maximal repression level. A variable kinetic of gene expression was also observed depending on the substrate $\left(\mathrm{NH}_{4}{ }^{+}, \mathrm{NO}_{2}{ }^{-}\right.$and $\left.\mathrm{NO}_{3}{ }^{-}\right)$. In fact, the differential expression obtained with the different $\mathrm{N}$ substrates suggests that the rate of gene repression depends on the position of the substrate in the pathway of nitrate assimilation. These results support the idea that the intracellular $\mathrm{N}$-metabolite accumulation coming from the nitrate assimilation pathway is involved in the regulation of TlNrt2.1 and TlNrt2.3 genes. In land plants, several studies have shown that the expression level of genes encoding NRT2 is quickly repressed by the metabolites generated through nitrate assimilation. In fact, ammonium and some amino acids supplied cause an inhibitory effect on nitrate transport. Krapp et al. (1998) showed a decrease of the NpNrt2 gene expression level in Nicotiana plumbaginifolia in the presence of glutamine (Krapp et al., 1998). Similarly, in A. thaliana, the addition of arginine to the medium resulted in a strong inhibition of AtNrt2.1 expression (Zhuo et al., 1999). In the green microalga $C$. reinhardtii, previous studies showed the repression of three CrNrt2 genes in the presence of ammonium (Quesada et al., 1998). Furthermore, Kang et al. (2009) reported that the inhibition of the GS/GOGAT enzymatic system removed the repression of total Nrt2 genes in I. galbana (haptophyte) and T. pseudonana (diatom). Our experiment reveals a regulation system of TINrt2.1 and TINrt2.3 genes consistent with those already described in plants and some microalgae. As expected, expression of the constitutive gene TINrt2.2 is not affected by this regulation system (Fig. 6B).

\section{TINrt2.4: an atypical putative high-affinity nitrate transporter in Tisochrysis lutea.}

In silico analysis of the TINRT2.4 protein revealed that this gene had some specificities that set it apart from other TINRT2 proteins (Fig. 1). Only TINRT2.4 harboured an atypical feature corresponding to the additional presence of $20 \mathrm{AA}$ at the end of the C-terminal domain. Moreover, no protein kinase $\mathrm{C}$ recognition motif (conserved or not in NRT2 family) was predicted from its protein sequence. 
Nevertheless, the highly conserved motif found in all NRT2 transporters (NRT2 and MFS motif) was clearly identified in the TINRT2.4 protein and strengthens its status as belonging to the NRT2 family. Very interestingly, the TINrt2.4 expression pattern was totally unexpected. In contrast to other inducible TINrt2 genes (TINrt2.1 and TINrt2.3), the mRNA abundance of TINrt2.4 was very weak during nitrogen starvation (Figs. 3E and 4E). This result could indicate that the TlNrt2.4 gene is not directly implicated in the N-starvation response, contrary to TINrt2.1 and TINrt2.3.

TlNrt2.4 expression was induced under nitrate-sufficient conditions $(200 \mu \mathrm{M})$, like TlNrt2.1 and TINrt2.3 genes, but its expression levels remained weak compared with these other genes (Fig. 3E). In contrast, in a way surprisingly unlike TlNrt2.1 and TINrt2.3, the TINrt2.4 expression level was induced under AN-sufficient conditions (Fig. 6D). Furthermore, quantitative RT-PCR studies of the TINrt2.4 gene revealed a slight yet significant expression during the ammonium batch experiment (Fig. 4E). This pattern contrasts with the repression of Nrt2 genes by ammonium, which is well described in many species (land plants and microalgae) (Forde, 2000; Koltermann et al., 2003; Krapp et al., 1998). Moreover, the TlNrt2.4 profile expression was inversely correlated with TlNrt2.1 and TlNrt2.3 transcriptional gene responses for almost all experiments.

Considering the atypical expression profile of TINrt2.4 gene, a possible relation between its expression and the cell $\mathrm{N}$ status has been hypothesised. For this purpose, we observed the evolution of TINrt2 gene expression versus the cell N/C quota during the ammonium batch culture (Fig. 5). The results exhibited three distinct patterns depending on the gene. TlNrt2.1 and TlNrt2.3 inducible genes were down- and up-regulated according to the nitrogen depletion (total depletion occurred after the highest $\mathrm{N} / \mathrm{C}$ ratio value) (Fig. 5A). As expected, the expression of the TlNrt2.2 constitutive gene was independent to both N/C ratios and residual nitrogen (Fig. 5B).

In contrast, the TINrt2.4 gene was expressed irrespective of the presence of ammonium substrate (Fig. 5C). In fact, for both of these residual nitrogen levels, high TINrt2.4 expression was observed when the cell quota was full. Conversely, expression of this gene was strongly repressed for an empty cell quota. This could mean that TlNrt2.4 expression would be linked to the cell $\mathrm{N}$ status with a significant threshold effect close to N/C = $0.11(\mathrm{P}<0.05 ; \mathrm{n}=21)$.

These results suggest that TINrt2.4 has a different role in the nitrogen transport and/or metabolism pathway. Among several hypotheses, TINRT2.4 could be involved in storage processes. This hypothesis would be supported by the presence of putative signal sorting in the C-terminal domain leading to a possibly different subcellular localization. Indeed, one study has even reported a storage function for the AtNrt2.7 gene in Arabidopsis thaliana seeds (Chopin et al., 2007). However, to date, none of the NRT2 proteins have been clearly localized in the intracellular compartment of microalgae. Alternatively, given its converse expression pattern, the TlNrt2.4 gene could be involved in a regulation system. Lastly, the TINrt2.4 gene could be a vestigial gene stimulated by $\mathrm{N}$ metabolism. Indeed, haptophytes, like other microalgae groups, are issued from secondary endosymbiosis, which implicates genomic rearrangement (McFadden, 2001). 
To our knowledge, this is the first time that this original expression profile for Ntr2 genes has been described. Today, the function of TlNrt2.4 gene remains unclear and further investigations will be necessary for to improve our understanding of its involvement in the nitrogen metabolism of T. lutea.

\section{Conclusion}

Due to its natural nutritional properties, the haptophyte T. lutea is commonly used as a feed in aquaculture. Recently, it has also been the subject of domestication for various applications (Cadoret et al., 2012). Beyond the obvious economic interest, there is also a fundamental interest in the Haptophyta lineage, which is highly diverse and ecologically dominant in ocean euphotic zones. To date, our understanding of the nitrogen metabolism of T. lutea is limited. Accordingly, it would be of great interest to understand the biology of $T$. lutea in relation to nitrogen availability. This first study is an attempt to further knowledge in this direction.

Four genes, encoding putative high-affinity nitrate/nitrite transporters, were identified, cloned and sequenced in T. lutea. In silico analysis revealed that the TINrt2 sequences did not contain introns, but had a unusual sequence of 100 AA forming an extracellular loop, whose function remains to be determined. This original additional sequence seems to be a particularity of the Haptophyta. The monitoring of individual TlNrt2 gene expression under different nitrogen sources highlights a differential expression profile that leads us to conclude that there are two inducible genes (TlNrt2.1 and TlNrt2.3), one constitutive gene (TlNrt2.2) and another gene characterized by an atypical expression profile (TINrt2.4). The expression of the TINrt2.4 gene appears to be independent of the substrate used, while that of the other TlNrt2 genes seems to be related to the residual nitrogen. From this preliminary study, it is hazardous to speculate on the role of each gene in sensing and/or uptake of nitrogen substrates. Further investigations need to be done to reveal the true function of high-affinity nitrate/nitrite transporters in T. lutea. As for most microalgae of interest, the lack of genetic tools prevents us from using mutants to characterize the true function and localization (using GFPchimeras) of these TlNrt2 genes in the cell.

Finally, this study contributes to an important topic of current research in plant nutrition via the analysis of nutrient transporter proteins, in our case those involved in nitrogen metabolism of microalgae. The understanding of microalgal nitrogen metabolism will provide us with fundamental knowledge but will also make a major contribution to the establishment of sustainable nitrogen management during biomass production with respect to the well-being of human populations.

\section{Author contributions}

AC wrote the manuscript. All cell culture experiments and sampling were performed by AC, JBB, FF AFC, CR and BSJ. Gene expression analyses were made by AC and FF. MG and JBB helped for homology tree analysis and figure design, respectively. GC helped with bioinformatic analyses. Molecular analyses (cloning, sequencing, etc.) were performed by AC and NS. Elementary analyses 
(N, C) were done by EL. GB, AC, JBB, JPC and BSJ conceived the study and the project was coordinated by GB and BSJ. All authors corrected and approved the final manuscript.

\section{Acknowledgments}

The authors are grateful to the anonymous reviewers for their critical comments that have greatly improved the manuscript. Thanks to Ms Deborah McCombie for the English reviewing of the manuscript.

\section{Funding}

This work was supported by the French region of Pays de la Loire ("Nouvelles équipes, nouvelles thématiques” program) and the French Research Institute for Exploitation of the Sea (IFREMER).

Conflicts of interest: No conflicts of interest declared.

\section{References}

Ahmad I, Hellebust JA (1984) Nitrogen Metabolism of the Marine Microalga Chlorella autotrophica. Plant Physiol. 76: 658-663

Aminot A, Kérouel R (2007) Dosage automatique des nutriments dans les eaux marines: méthodes en flux continu (Editions Quae)

de Angeli A, Monachello D, Ephritikhine G, Frachisse JM, Thomine S, Gambale F, Barbier-Brygoo H (2006) The nitrate/proton antiporter AtCLCa mediates nitrate accumulation in plant vacuoles. Nature 442: 939-942.

Bannai H, Tamada Y, Maruyama O, Nakai K, Miyano S (2002) Extensive feature detection of Nterminal protein sorting signals. Bioinformatics 18: 298-305

Becker B (2007) Function and evolution of the vacuolar compartment in green algae and land plants (Viridiplantae). Int. Rev. Cytol. 264: 1-24

Bendif EM, Probert I, Schroeder DC, de Vargas C (2013) On the description of Tisochrysis lutea gen. nov. sp. nov. and Isochrysis nuda sp. nov. in the Isochrysidales, and the transfer of Dicrateria to the Prymnesiales (Haptophyta). J. Appl. Phycol. 1-14

Bhadury P, Song B, Ward BB (2011) Intron features of key functional genes mediating nitrogen metabolism in marine phytoplankton. Mar. Genomics 4: 207-213

Blom N, Gammeltoft S, Brunak S (1999) Sequence and structure-based prediction of eukaryotic protein phosphorylation sites. J. Mol. Biol. 294: 1351-1362

Bougaran G, Le Déan L, Lukomska E, Kaas R, Baron, R. (2003) Transient initial phase in continuous culture of Isochrysis galbana affinis Tahiti. Aquat. Living Resour. 16: 389-394

Brownlee AG, Arst HN (1983) Nitrate uptake in Aspergillus nidulans and involvement of the third gene of the nitrate assimilation gene cluster. J. Bacteriol. 155: 1138-1146 
Cadoret J-P, Garnier M, Saint-Jean B (2012) Microalgae, Functional Genomics and Biotechnology. In Advances in Botanical Research, Elsevier, pp. 285-341

Cai C, Wang J-Y, Zhu Y-G, Shen Q-R, Li B, Tong Y-P, Li Z-S (2008) Gene structure and expression of the high-affinity nitrate transport system in rice roots. J. Integr. Plant Biol. 50: 443-451

Carrier G, Garnier M, Le Cunff L, Bougaran G, Probert I, De Vargas C, Corre E, Cadoret J-P, SaintJean B (2014) Comparative transcriptome of wild type and selected strains of the microalgae Tisochrysis lutea provides insights into the genetic basis, lipid metabolism and the life cycle. PLoS ONE 9 (1): e86889. doi:10.1371/journal.pone.0086889

Chopin F, Orsel M, Dorbe M-F, Chardon F, Truong H-N, Miller AJ, Krapp A, Daniel-Vedele F (2007) The Arabidopsis ATNRT2.7 Nitrate Transporter Controls Nitrate Content in Seeds. Plant Cell Online 19: 1590-1602

Chung C-C, Hwang S-PL, Chang J (2003) Identification of a High-Affinity Phosphate Transporter Gene in a Prasinophyte Alga, Tetraselmis chui, and Its Expression under Nutrient Limitation. Appl. Environ. Microbiol. 69: 754-759

Collos Y, Vaquer A, Souchu P (2005) Acclimation of Nitrate Uptake by Phytoplankton to High Substrate Levels. J. Phycol. 41: 466-478

Crawford NM, Forde BG (2002) Molecular and developmental biology of inorganic nitrogen nutrition. The Arabidopsis Book 1: e0011, doi/10.1199/tab.0011

Crawford NM, Glass AD (1998) Molecular and physiological aspects of nitrate uptake in plants. Trends Plant Sci. 3: 389-395

Daniel-Vedele F, Filleur S, Caboche M (1998) Nitrate transport: a key step in nitrate assimilation. Curr. Opin. Plant Biol. 1: 235-239

Dechorgnat J, Patrit O, Krapp A, Fagard M, Daniel-Vedele F (2012) Characterization of the Nrt2.6 gene in Arabidopsis thaliana: a link with plant response to biotic and abiotic stress. PLoS ONE 7(8): e42491. doi:10.1371/journal.pone.0042491

Dereeper A, Guignon V, Blanc G, Audic S, Buffet S, Chevenet F, Dufayard JF, Guindon S, Lefort V, Lescot M (2008). Phylogeny.fr: robust phylogenetic analysis for the non-specialist. Nucleic Acids Res. 3: 465-469

Due AD, Qu Z, Thomas JM, Buchs A, Powers AC, May JM (1995) Role of the C-terminal tail of the GLUT1 glucose transporter in its expression and function in Xenopus laevis oocytes. Biochemistry 34(16): 5462-5471

Fernandez E, Galvan A (2007) Inorganic nitrogen assimilation in Chlamydomonas. J. Exp. Bot. 58: 2279-2287

Fernandez E, Galvan A (2008) Nitrate Assimilation in Chlamydomonas. Eukaryot. Cell 7: 555-559 Forde BG (2000) Nitrate transporters in plants: structure, function and regulation. Biochim. Biophys. Acta BBA - Biomembr. 1465: 219-235. 
Galvan, A. and Fernández, E. (2001) Eukaryotic nitrate and nitrite transporters. Cell. Mol. Life Sci. CMLS 58: 225-233

Galván A, Quesada A, Fernández E (1996) Nitrate and Nitrite Are Transported by Different Specific Transport Systems and by a Bispecific Transporter in Chlamydomonas reinhardtii. J. Biol. Chem. 271: 2088-2092.

Glass ADM, Shaff JE, Kochian LV (1992) Studies of the Uptake of Nitrate in Barley. IV. Electrophysiology. Plant Physiol. 99: 456-463

He Q, Qiao D, Zhang Q, Li Y, Xu H, Wei L, Gu Y, Cao Y (2004) Cloning and expression study of a putative high-affinity nitrate transporter gene from Dunaliella salina. J. Appl. Phycol. 16: 395400

Hildebrand M, Dahlin K (2000). Nitrate transporter genes from the diatom Cylindrotheca fusiformis (Baccillariophyceae): mRNA levels controlled by nitrogen sources and by the cell cycle. J. Phycol. 36: 702-713

Hofmann K (1993) TMbase - A database of membrane spanning proteins segments. Biol Chem Hoppe-Seyler 374

Horton P, Park K-J, Obayashi T, Fujita N, Harada H, Adams-Collier CJ, Nakai K (2007) WoLF PSORT: protein localization predictor. Nucleic Acids Res. 35: W585-W587

Kang L-K, Hwang SPL, Gong GC, Lin HJ, Chen PC, Chang J (2007) Influences of nitrogen deficiency on the transcript levels of ammonium transporter, nitrate transporter and glutamine synthetase genes in Isochrysis galbana (Isochrysidales, Haptophyta). Phycologia 46: 521-533

Katagiri H, Asano T, Ishihara H, Tsukuda K, Lin JL, Inukai K, Kikuchi M, Yazaki Y, Oka Y (1992) Replacement of intracellular C-terminal domain of GLUT1 glucose transporter with that of GLUT2 increases Vmax and Km of transport activity. J. Biol. Chem. 267: 22550-22555

Koltermann M, Moroni A, Gazzarini S, Nowara D, Tischner R (2003). Cloning, functional expression and expression studies of the nitrate transporter gene from Chlorella sorokiniana (strain 211-8k). Plant Mol. Biol. 52: 855-864

Krapp A, Fraisier V, Scheible WR, Quesada A, Gojon A, Stitt M, Caboche M, Daniel-Vedele F (1998) Expression studies of $N r t 2: 1 N p$, a putative high-affinity nitrate transporter: evidence for its role in nitrate uptake. Plant J. 14: 723-731

Léran S, Varala K, Boyer JC, Chiurazzi M, Crawford N, Daniel-Vedele F, David L, Dickstein R, Fernandez E, Forde B, Gassmann W, Geiger D, Gojon A, Gong JM, Halkier BA, Harris JM, Hedrich R, Limami AM, Rentsch D, Seo M, Tsay YF, Zhang M, Coruzzi G, Lacombe B (2014) A unified nomenclature of NITRATE TRANSPORTER 1/PEPTIDE TRANSPORTER family members in plants. Trends Plant Sci. 1: 5-9

Li Q, Gao X, Sun Y, Zhang Q, Song R, Xu Z (2006) Isolation and characterization of a sodiumdependent phosphate transporter gene in Dunaliella viridis. Biochem. Biophys. Res. Commun. 340(1): 95-104 
Liu H, Xiong S, Shi Y, Samuel SJ, Lachaal M, Jung CY (1995) ATP-sensitive Binding of a 70-kDa Cytosolic Protein to the Glucose Transporter in Rat Adipocytes. J. Biol. Chem. 270: 7869-7875

Liu KH, Huang CY, Tsay YF (1999) CHL1 Is a Dual-Affinity Nitrate Transporter of Arabidopsis Involved in Multiple Phases of Nitrate Uptake. Plant Cell Online 11: 865-874

Lomas MW, Glibert PM (2000) Comparisons of Nitrate Uptake, Storage, and Reduction in Marine Diatoms and Flagellates. J. Phycol. 36: 903-913

Matsuda Y, Colman B (1995) Induction of $\mathrm{CO}_{2}$ and Bicarbonate Transport in the Green Alga Chlorella ellipsoidea (II. Evidence for Induction in Response to External CO2 Concentration). Plant Physiol. 108: 253-260

McDonald SM, Plant JN, Worden AZ (2010) The Mixed Lineage Nature of Nitrogen Transport and Assimilation in Marine Eukaryotic Phytoplankton: A Case Study of Micromonas. Mol. Biol. Evol. 27: $2268-2283$

McFadden GI (2001) Primary and Secondary Endosymbiosis and the Origin of Plastids. J. Phycol. 37: 951-959

Miller AJ, Fan X, Shen Q, Smith SJ (2008) Amino acids and nitrate as signals for the regulation of nitrogen acquisition. J. Exp. Bot. 59: 111-119

Nakamura Y, Umemiya Y, Masuda K, Inoue H, Fukumoto M (2007) Molecular cloning and expression analysis of cDNAs encoding a putative Nrt2 nitrate transporter from peach. Tree Physiol. 27: 503-510

Okamoto M, Vidmar JJ, Glass ADM (2003) Regulation of NRT1 and NRT2 gene families of Arabidopsis thaliana: responses to nitrate provision. Plant Cell Physiol. 44: 304-317

Orsel M, Krapp A, Daniel-Vedele F (2002) Analysis of the NRT2 Nitrate Transporter Family in Arabidopsis. Structure and Gene Expression. Plant Physiol. 129: 886-896

Orsel M, Chopin F, Leleu O, Smith SJ, Krapp A, Daniel-Vedele F, Miller AJ (2006) Characterization of a two-component high-affinity nitrate uptake system in Arabidopsis. Physiology and proteinprotein interaction. Plant Physiol. 142: 1304-1317

Pao SS, Paulsen IT, Saier MH (1998) Major Facilitator Superfamily. Microbiol. Mol. Biol. Rev. 62: $1-34$

Petersen TN, Brunak S, von Heijne G, Nielsen H (2011) SignalP 4.0: discriminating signal peptides from transmembrane regions. Nat. Methods 8: 785-786

Plett D, Toubia J, Garnett T, Tester M, Kaiser BN, Baumann U (2010) Dichotomy in the NRT Gene Families of Dicots and Grass Species. PLoS ONE 5(12): e15289

Quesada A, Galvan A, Fernandez E (1994) Identification of nitrate transporter genes in Chlamydomonas reinhardtii. Plant J. 5: 407-419

Quesada A, Hidalgo J, Fernández E (1998) Three Nrt2 genes are differentially regulated in Chlamydomonas reinhardtii. Mol. Gen. Genet. 25(4): 373-377 
Rexach J, Montero B, Fernández E, Galván A (1999) Differential Regulation of the High Affinity Nitrite Transport Systems III and IV in Chlamydomonas reinhardtii. J. Biol. Chem. 274: 2780127806

Rexach J, Llamas A, Fernández E, Galván A (2002) The activity of the high-affinity nitrate transport system I (NRT2;1, NAR2) is responsible for the efficient signalling of nitrate assimilation genes in Chlamydomonas reinhardtii. Planta 215: 606-611

Siddiqi MY, Glass ADM, Ruth TJ, Rufty TW (1990) Studies of the Uptake of Nitrate in Barley. Plant Physiol. 93(4): 1426-1432

Slot JC, Hallstrom KN, Matheny PB, Hibbett DS (2007) Diversification of NRT2 and the Origin of Its Fungal Homolog. Mol. Biol. Evol. 24: 1731-1743

Song B, Ward BB (2007) Molecular Cloning and Characterization of High-Affinity Nitrate Transporters in Marine Phytoplankton. J. Phycol. 43: 542-552

Steiner HY, Naider F, Becker JM (1995) The PTR family: a new group of peptide transporters. Mol. Microbiol. 16: 825-834

Tong Y, Zhou JJ, Li Z, Miller AJ (2005) A two-component high-affinity nitrate uptake system in barley. Plant J. 41: 442-450

Trueman LJ, Richardson A, Forde BG (1996) Molecular cloning of higher plant homologues of the high-affinity nitrate transporters of Chlamydomonas reinhardtii and Aspergillus nidulans. Gene 175: 223-231

Tsay YF, Chiu CC, Tsai CB, Ho CH, Hsu PK (2007) Nitrate transporters and peptide transporters. FEBS Lett. 581: 2290-2300

Ullrich WR (1983) Uptake and Reduction of Nitrate: Algae and Fungi. Encyclopedia of Plant Physiology, Springer Berlin Heidelberg, Volume 15, pp. 376-397

Unkles SE, Hawker KL, Grieve C, Campbell EI, Montague P, Kinghorn JR (1991) crnA encodes a nitrate transporter in Aspergillus nidulans. Proc. Natl. Acad. Sci. 88: 204-208

Vidmar JJ, Zhuo D, Siddiqi MY, Schjoerring JK, Touraine B, Glass ADM (2000) Regulation of HighAffinity Nitrate Transporter Genes and High-Affinity Nitrate Influx by Nitrogen Pools in Roots of Barley. Plant Physiol. 123: 307-318

Walne P (1966) Experiments in the large-scale culture of the larvae of Ostrea edulis L. H.M.S.O. eds, London

Wang R, Liu D, Crawford NM (1998) The Arabidopsis CHL1 protein plays a major role in highaffinity nitrate uptake. Proc. Natl. Acad. Sci. 95: 15134-15139

Zhuo D, Okamoto M, Vidmar JJ, Glass ADM (1999) Regulation of a putative high-affinity itrate transporter (Nrt2;1At) in roots ofArabidopsis thaliana. Plant J. 17: 563-568 


\section{Supporting Information}

Additional Supporting Information may be found in the online version of this article:

Appendix S1. List of primers used for TlNrt2 gene cloning.

Appendix S2. List of RT-Q-PCR primers used for TINrt2 gene expression.

Appendix S3. Comparative analyses of TINrt2 sequences.

Appendix S4. Comparison of the amino acid sequences of TINRT2 with NRT2 sequences from Aspergillus nidulans, Hansenula polymorpha, Arabidopsis thaliana, Oriza sativa, Chlamydomonas reinhardtii and Dunaliella salina.

Appendix S5. Proteomic identification of the atypical sequence in Tisochrysis lutea. 


\section{Figure legends:}

Fig. 1. Alignment of NRT2 protein sequences from Aspergillus nidulans, Hansenula polymorpha, Arabidopsis thaliana, Oriza sativa, Dunaliella salina and Tisochrysis lutea. Alignment was performed with ClustalW. Sequence identities are indicated by a black background and homologies by a grey background.

Fig. 2. Homology tree of high-affinity nitrate transporters (NRT2) composed of 37 NRT2 sequences from bacteria, yeast, fungi, algae and land plants. Accession numbers are given in the Material and Methods section. The amino acid sequences were aligned using MUSCLE software and the phylogeny tree built in PhyML software (Dereeper et al., 2008).

Fig. 3. Various parameters of Tisochrysis lutea cells grown in nitrate batch culture. Axenic preculture of Tisochrysis lutea was grown in a Conway medium with $1 \mathrm{mM} \mathrm{NaNO}$. During exponential phase, cells were inoculated into a new modified Conway medium containing $200 \mu \mathrm{M} \mathrm{NaNO}$. (A) concentrations of particular carbon (measured using a CN elemental analyzer) and residual nitrate (measured using an automated spectrophotometric method) $(\mu \mathrm{M})$ during the batch culture (B) relative mRNA abundance of TlNrt2.1 (C) relative mRNA abundance of TlNrt2.2 (D) relative mRNA abundance of TlNrt2.3 (E) relative mRNA abundance of TINrt2.4. Each value represents the mean \pm SE of three independent experiments.

Fig. 4. Various parameters of Tisochrysis lutea cells grown in ammonium batch culture. Axenic

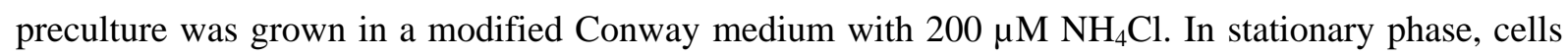
with an empty quota were inoculated into non-enriched seawater for 24 hours in order to lower the natural nitrogen content of the seawater. Then, a new modified Conway medium with $200 \mu \mathrm{M} \mathrm{NH} \mathrm{NH}_{4} \mathrm{Cl}$ was added (arrow on the temporal axis). (A) Concentration of particular carbon and residual nitrate $(\mu \mathrm{M})$ during the batch culture (B) relative mRNA abundance of TINrt2.1 (C) relative mRNA abundance of TINrt2.2 (D) relative mRNA abundance of TINrt2.3 (E) relative mRNA abundance of TINrt2.4. Each value represents the mean \pm SE of three independent experiments.

Fig. 5. Relative mRNA abundance of TlNrt2 genes versus the N/C cellular ratio (N-status) in the ammonium batch culture of Tisochrysis lutea. The initial condition (N-starved) is figured by a filled symbol and the timeline of the culture is initiated by an arrow. Culture was enriched with $200 \mu \mathrm{M}$ ammonium immediately after the first sampling. The numbers represent the residual ammonium concentrations $(\mu \mathrm{M})$. N/C ratios were calculated by dividing the particulate $\mathrm{N}$ concentration by the particulate C concentration. (A) Relative mRNA abundance of TlNrt2.1 and TlNrt2.3 genes (B) TlNrt2.2 gene and (C) TINrt2.4 gene versus the N/C cellular ratio. 
Fig. 6. Effect of different $\mathrm{N}$-substrates on transcript levels of TINrt2 genes. After $\mathrm{N}$ starvation, Tisochrysis lutea cells were inoculated with different forms of nitrogenous nutrients (1 $\mathrm{mM}$ of total nitrogen). RNA extractions were performed at 0, 15, 30, 60, $120 \mathrm{~min}$. Graphs represent the expression profiles of each TlNrt2 genes under the different $\mathrm{N}$-substrate conditions. Each value represents the mean \pm SE of three independent experiments.

Appendix S1. List of primers used for TlNrt2 gene cloning.

Appendix S2. List of RT-Q-PCR primers used for TlNrt2 gene expression.

Appendix S3. Comparative analyses of TINrt2 sequences. (A) Identities of nucleotide sequences of TINrt2 genes (B) Identity and similarity analysis of amino acid sequences. Id: identities and Sim: similarities; all values are indicated in percentages.

Appendix S4. Comparison of the amino acid sequences of TINRT2 with NRT2 sequences from Aspergillus nidulans, Hansenula polymorpha, Arabidopsis thaliana, Oriza sativa, Chlamydomonas reinhardtii and Dunaliella salina. Id: identities and Sim: similarities; all values are indicated in percentages.

Appendix S5. Proteomic identification of the atypical sequence in Tisochrysis lutea. Alignment of TINRT2.1 protein with some peptides identified by shotgun proteomic analysis performed on Tisochrysis lutea. The atypical sequence harboured by TINRT2 proteins was boxed. Two peptides (peptides 6 and 7) were identified on the atypical sequence of all TINRT2 proteins. 


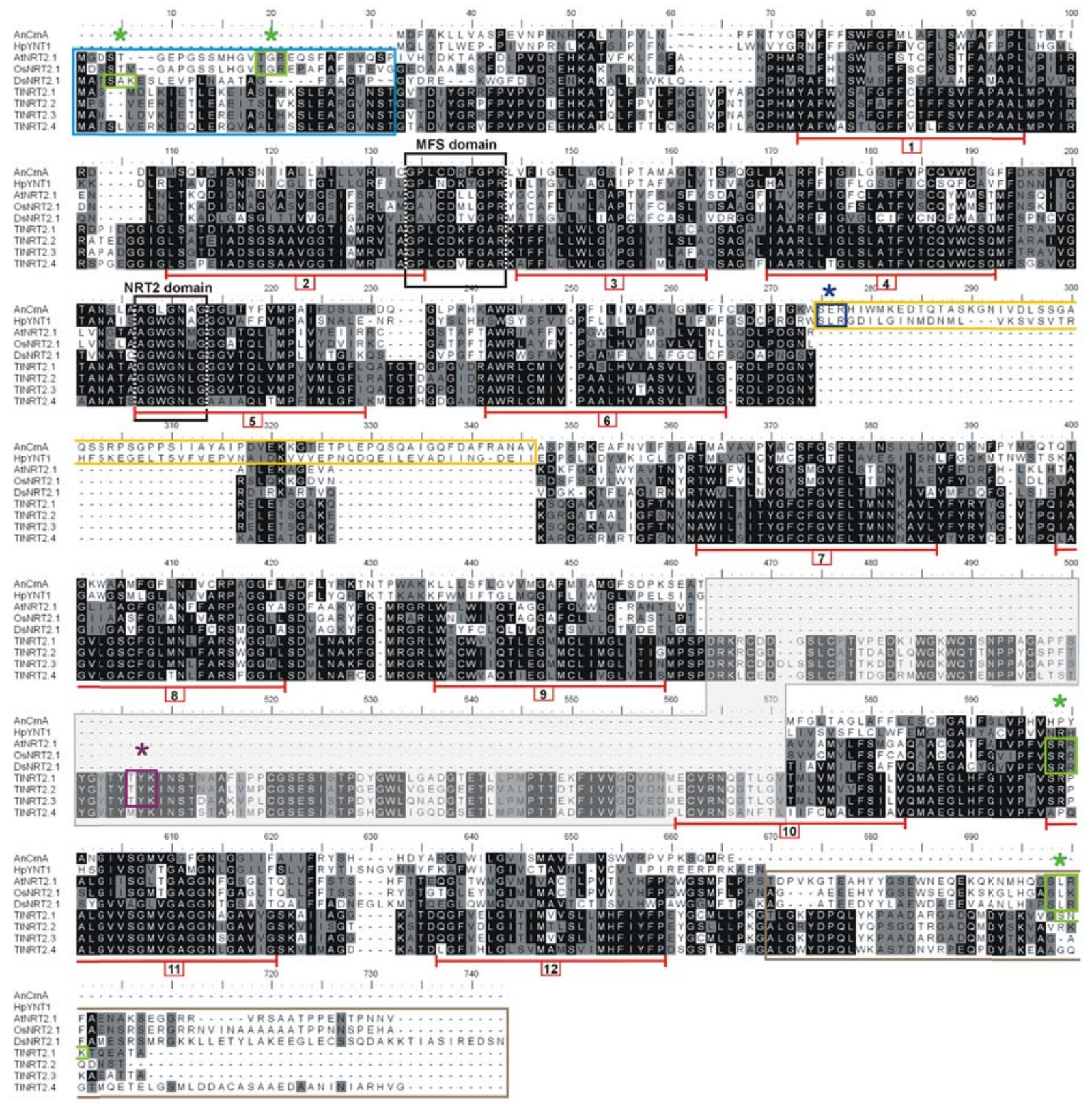

\begin{tabular}{|c|c|c|c|}
\hline$\square$ & Transmembrane domain & * & Conserved protein kinase $\mathrm{C}$ recognition motif \\
\hline & Extended $\mathrm{N}$-terminal sequence for plants and microalgae & & \\
\hline & Extended C-terminal sequence for plants and microalgae & $\pi$ & Protein kinase $\mathrm{C}$ recognition motif in TINRT2 \\
\hline & Large cytosolic loop for fungi and yeast & + & \\
\hline & Atypical loop for TINRT2 & \begin{tabular}{|c} 
\\
\end{tabular} & 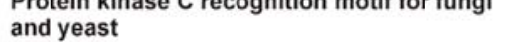 \\
\hline
\end{tabular}




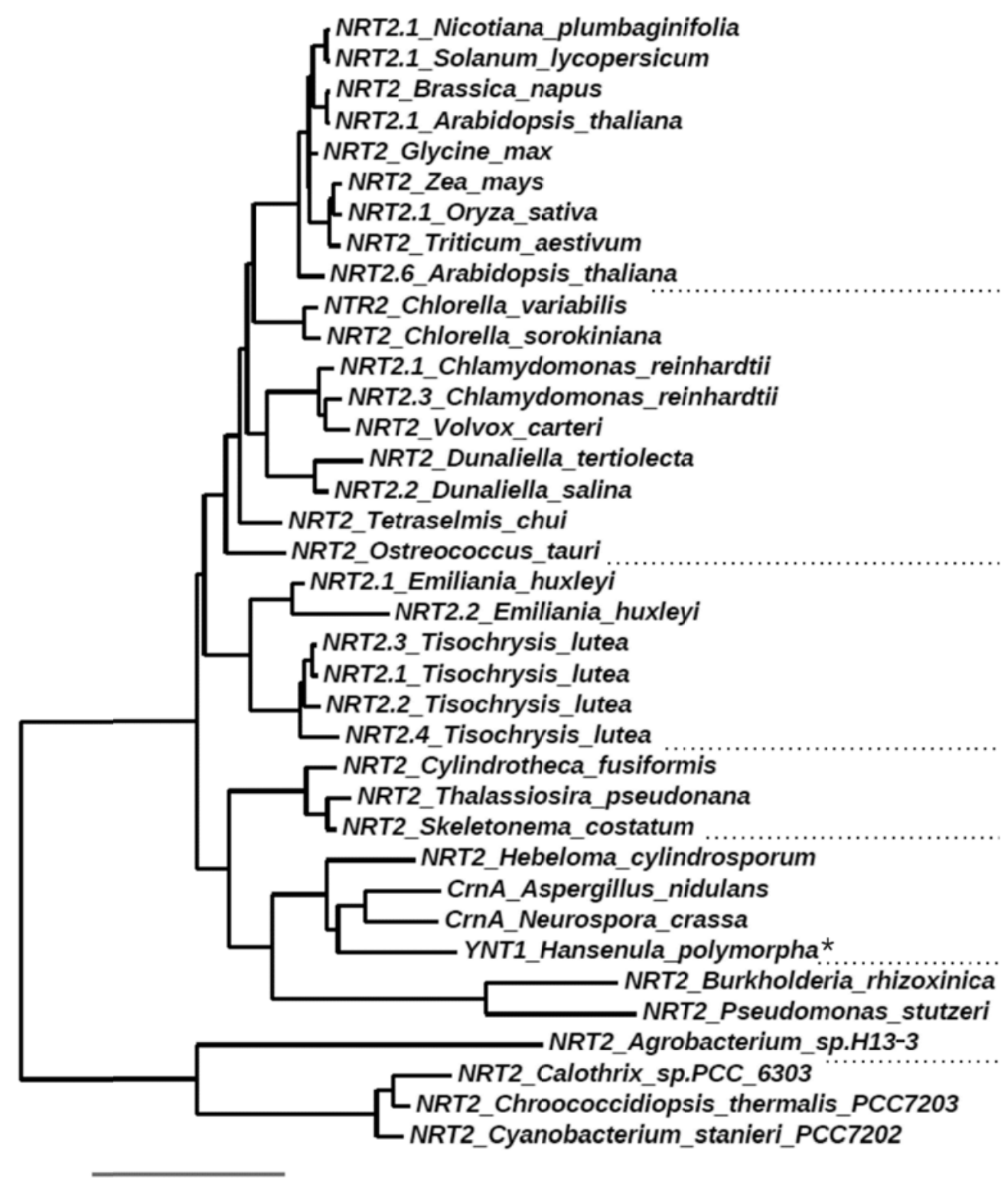



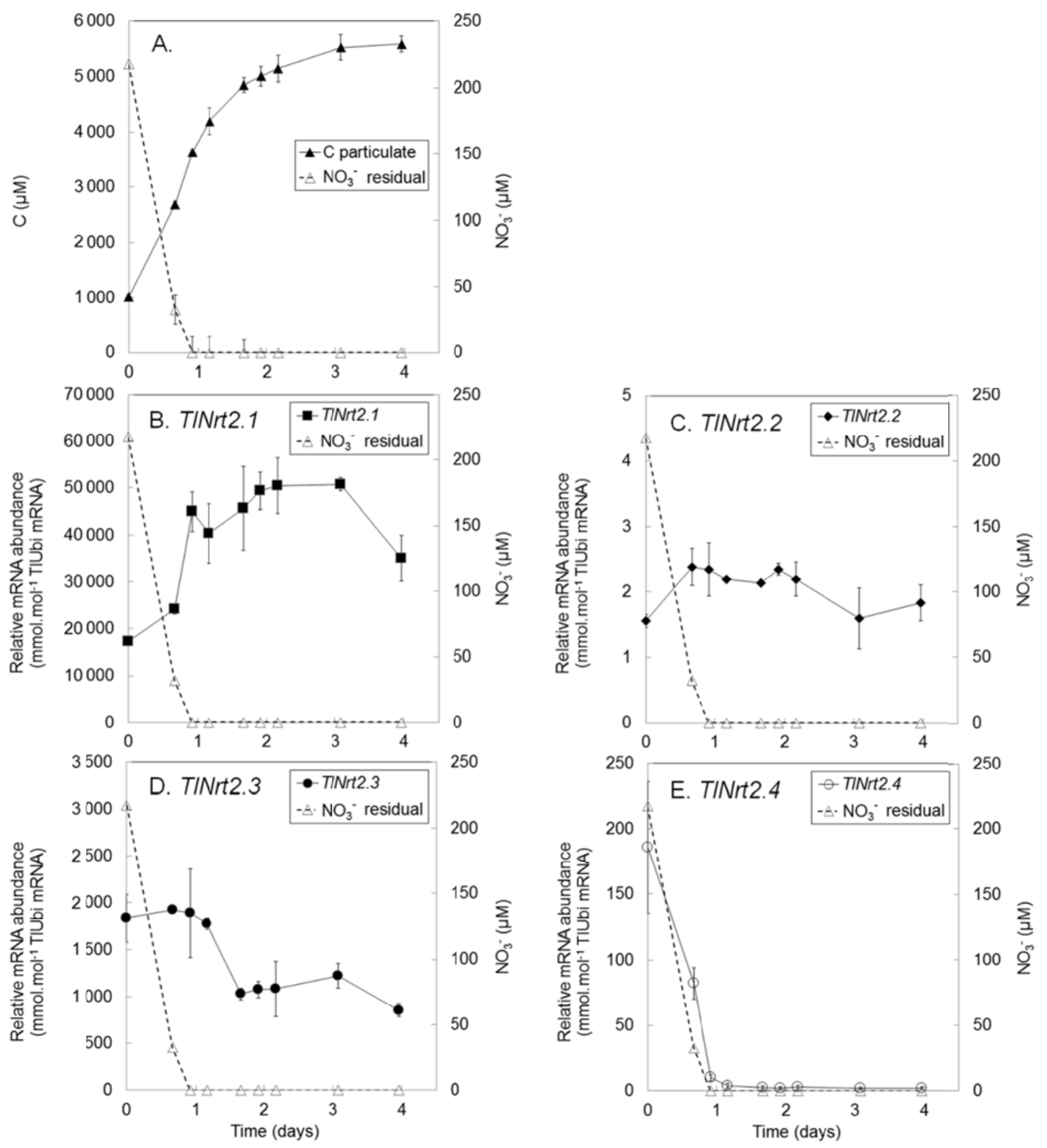

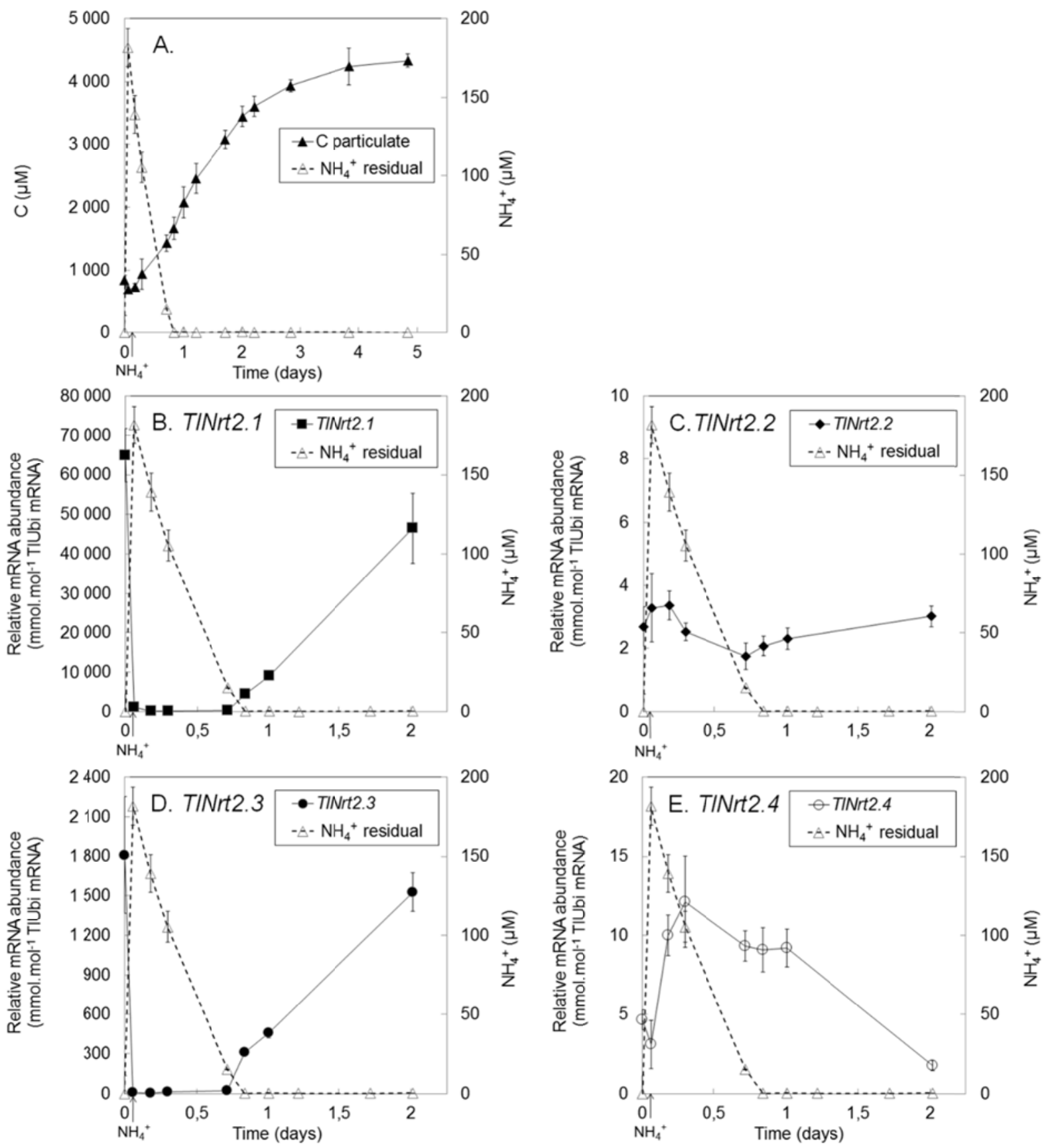

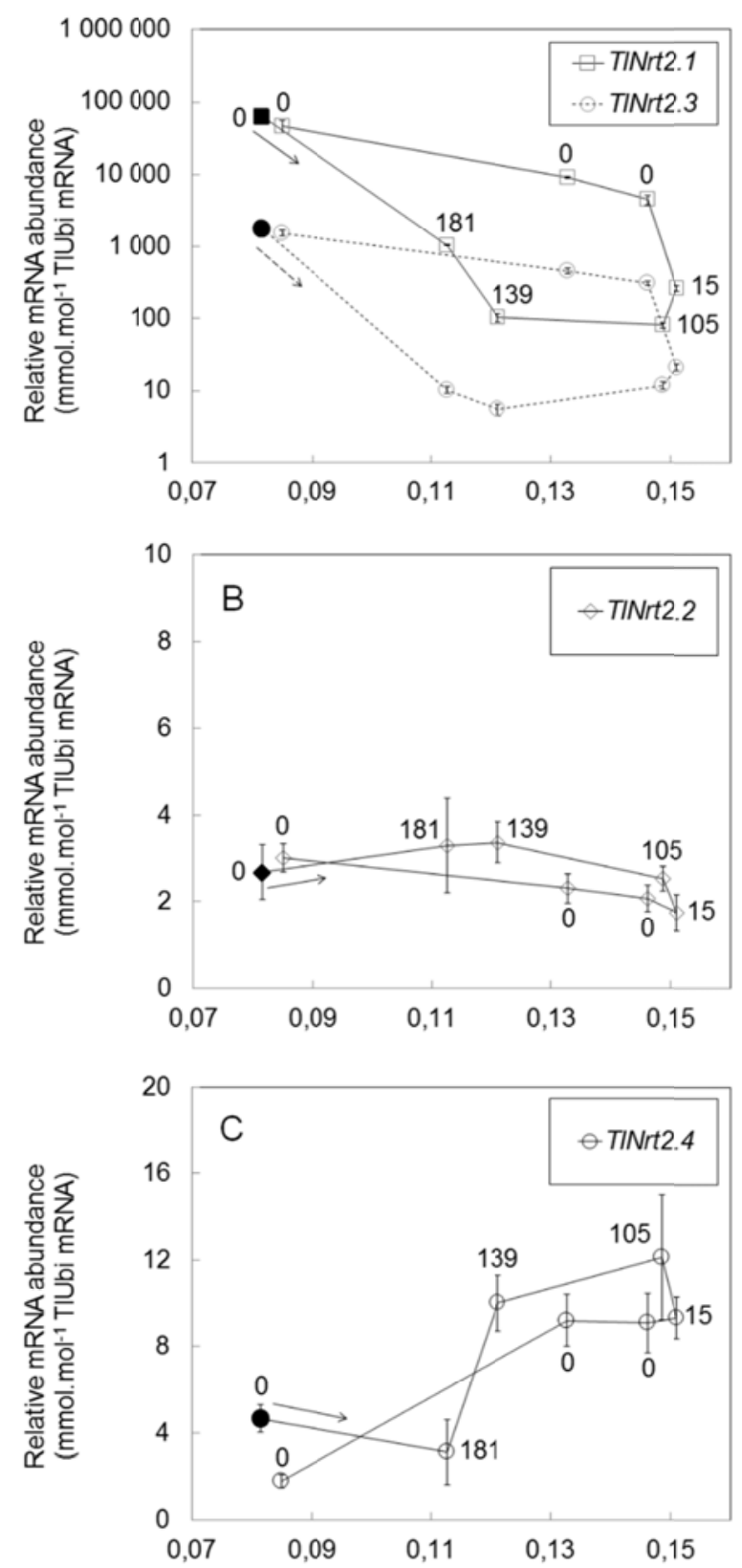

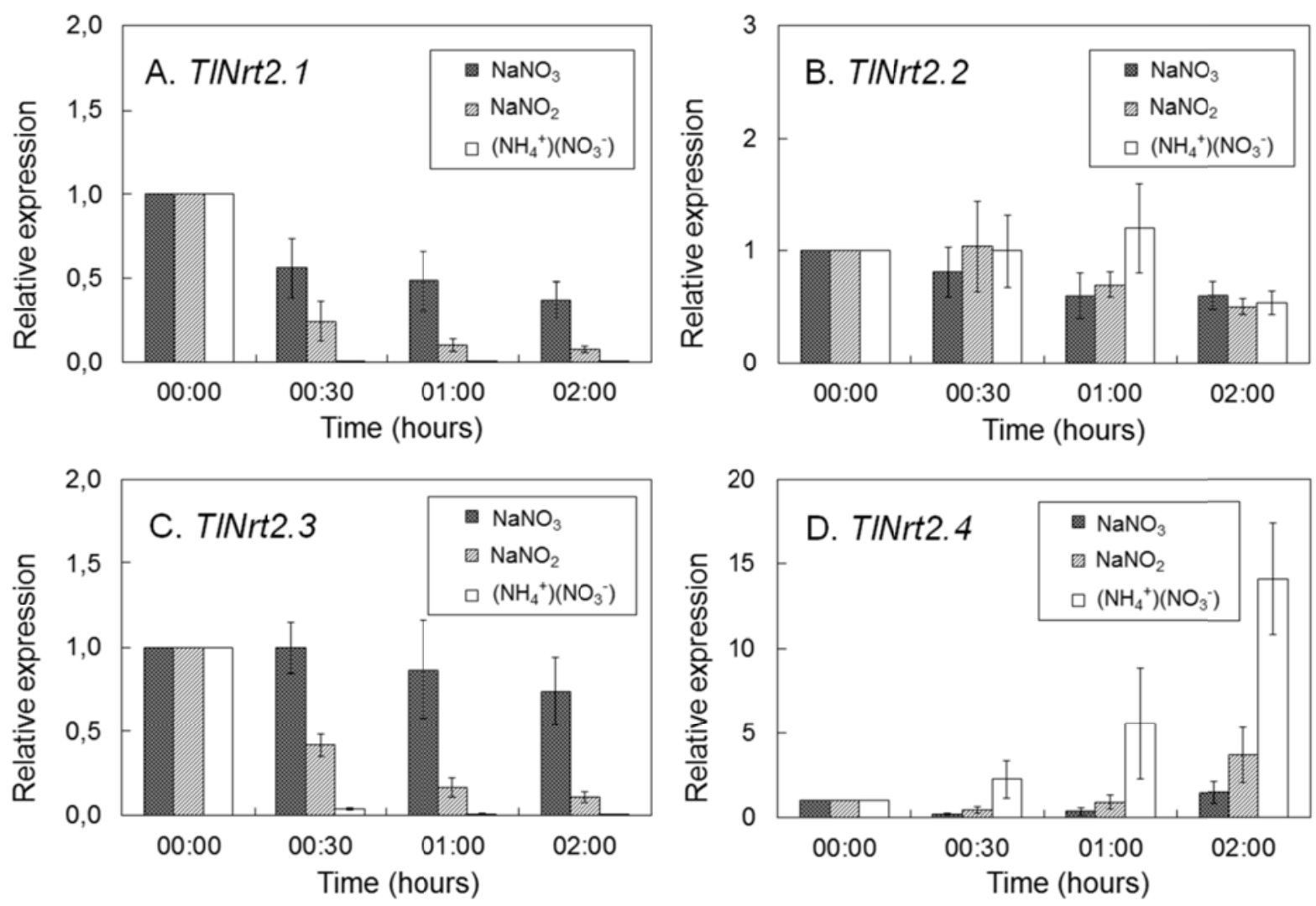


\begin{tabular}{|c|c|c|c|}
\hline Gene target & Primer & $\begin{array}{l}\text { Primer nucleotide sequence } \\
\qquad\left(5^{\prime}-3^{\prime}\right)\end{array}$ & $\begin{array}{l}\text { Amplicon } \\
\text { size (bp) }\end{array}$ \\
\hline \multirow[t]{2}{*}{ TINrt2.1 } & Forward & TCTCCCCAATCGTCTCGC & 2115 \\
\hline & Reverse & CAACCCTGCAACGCTCTCAC & \\
\hline \multirow[t]{2}{*}{ TINrt2.2 } & Forward & AACCCTTTGACGGCTCCAG & 2463 \\
\hline & Reverse & TGGCGATTGATTCACCTTGC & \\
\hline \multirow[t]{2}{*}{ TINrt2.3 } & Forward & TCСССТАССАСАTССTCG & 2278 \\
\hline & Reverse & AATCGTAGCGTGAGACATCG & \\
\hline \multirow[t]{2}{*}{ TINrt2.4 } & Forward & CGCTTCCATCTGTATTGTCC & 2333 \\
\hline & Reverse & CGTTGTTAGCTTTGCGTTAGG & \\
\hline \multirow[t]{2}{*}{ Gene target } & Primer & Primer nucleotide sequence & Amplicon \\
\hline & & $\left(5^{\prime}-3^{\prime}\right)$ & size (bp) \\
\hline \multirow[t]{2}{*}{ TINrt2.1 } & Forward & AAAACCCAAGAGGCTACTGC & 100 \\
\hline & Reverse & CGTACGTAGCGGTTAGTCG & \\
\hline \multirow[t]{2}{*}{ TINrt2.2 } & Forward & CAAATTGTGTTTGCGTTGC & 193 \\
\hline & Reverse & GGGAAGGCTTCGAATAACC & \\
\hline \multirow[t]{2}{*}{ TINrt2.3 } & Forward & CGACCACCGCTTGAGCC & 129 \\
\hline & Reverse & CAATGGGCACCTGAACGG & \\
\hline \multirow[t]{2}{*}{ TINrt2.4 } & Forward & AATGCAGGAAACTGAGTTGG & 168 \\
\hline & Reverse & ACTCGAGGCACAAGTTGC & \\
\hline \multirow[t]{2}{*}{ UBI } & Forward & AACTGTGGAGGTGGAGGAGT & 141 \\
\hline & Reverse & TTGTAGTCGCCAATCGTCTT & \\
\hline \multirow[t]{2}{*}{ GAPDH } & Forward & CGGTGCTCAATGTAGTGGTT & 150 \\
\hline & Reverse & TAGTGATCATGCCCTTCTCG & \\
\hline
\end{tabular}




\begin{tabular}{|c|c|c|c|c|c|c|c|}
\hline $\mathrm{A}$ & Gene & & TlNrt2.1 & \multicolumn{2}{|c|}{ TlNrt2.2 } & TlNrt2.3 & TlNrt2.4 \\
\hline & TlNrt2.1 & & 100 & \multicolumn{2}{|c|}{75.8} & 82.8 & 68.4 \\
\hline & TINrt2.2 & & 75.8 & \multicolumn{2}{|c|}{100} & 79.1 & 70.1 \\
\hline & TlNrt2.3 & & 82.8 & \multicolumn{2}{|c|}{79.1} & 100 & 70 \\
\hline & TINrt2.4 & & 68.4 & \multicolumn{2}{|c|}{70.5} & 70 & 100 \\
\hline B & \multicolumn{2}{|l|}{ Protein } & TINRT2.1 & \multicolumn{2}{|c|}{ TINRT2.2 } & TINRT2.3 & TINRT2.4 \\
\hline & \multirow{2}{*}{\multicolumn{2}{|c|}{ TINRT2.1 }} & Id 100 & \multicolumn{2}{|c|}{ Id 80.0} & Id 92.9 & Id 65.1 \\
\hline & & & $\operatorname{Sim} 100$ & \multicolumn{2}{|c|}{ Sim 89.1} & Sim 95.7 & $\operatorname{Sim} 76.5$ \\
\hline & \multirow{2}{*}{\multicolumn{2}{|c|}{ TINRT2.2 }} & Id 80.0 & \multicolumn{2}{|c|}{ Id 100} & Id 80.6 & Id 65.1 \\
\hline & & & Sim 89.1 & \multicolumn{2}{|c|}{ Sim 100} & Sim 88.7 & Sim 74.8 \\
\hline & \multirow{2}{*}{\multicolumn{2}{|c|}{ TINRT2.3 }} & Id 92.9 & \multicolumn{2}{|c|}{ Id 80.6} & Id 100 & Id 65.2 \\
\hline & & & $\operatorname{Sim} 95.7$ & \multicolumn{2}{|c|}{ Sim 88.7} & Sim 100 & $\operatorname{Sim} 76.1$ \\
\hline & \multirow{2}{*}{\multicolumn{2}{|c|}{ TINRT2.4 }} & Id 65.1 & \multirow{2}{*}{\multicolumn{2}{|c|}{$\begin{array}{c}\text { Id } 65.1 \\
\text { Sim } 74.8\end{array}$}} & Id 65.2 & Id 100 \\
\hline & & & $\operatorname{Sim} 76.5$ & & & Sim 76.1 & Sim 100 \\
\hline Protein & AnCrnA & HpYNT1 & AtNRT2.1 & OsNRT2 & CrNRT2.3 & DsNRT2.1 & \\
\hline \multirow{2}{*}{ TINRT2.1 } & Id 27.1 & Id 26.2 & Id 32.7 & $\operatorname{ld} 34.2$ & Id 34.0 & Id 34 & \\
\hline & $\operatorname{Sim} 41.8$ & $\operatorname{Sim} 40.2$ & $\operatorname{Sim} 45.6$ & Sim 47.2 & $\operatorname{Sim} 46.5$ & $\operatorname{Sim} 48.8$ & \\
\hline \multirow{2}{*}{ TINRT2.2 } & Id 28.2 & Id 26.7 & Id 34.3 & Id 34.4 & Id 34.7 & Id 33.1 & \\
\hline & Sim 43.1 & Sim 39.9 & $\operatorname{Sim} 47.2$ & Sim 47.4 & $\operatorname{Sim} 46.7$ & Sim 48.1 & \\
\hline \multirow{2}{*}{ TINRT2.3 } & Id 26.7 & Id 26.4 & Id 32.9 & Id 34.5 & Id 32.3 & Id 34.9 & \\
\hline & $\operatorname{Sim} 41.8$ & $\operatorname{Sim} 40.9$ & $\operatorname{Sim} 45.1$ & Sim 46.6 & $\operatorname{Sim} 44.5$ & $\operatorname{Sim} 46.9$ & \\
\hline \multirow{2}{*}{ TINRT2.4 } & Id 26.2 & Id 23.1 & Id 28.5 & Id 32.5 & Id 31.6 & Id 32.8 & \\
\hline & $\operatorname{Sim} 36.5$ & $\operatorname{Sim} 37.2$ & $\operatorname{Sim} 39.6$ & Sim 45.0 & $\operatorname{Sim} 44.4$ & $\operatorname{Sim} 45.6$ & \\
\hline
\end{tabular}




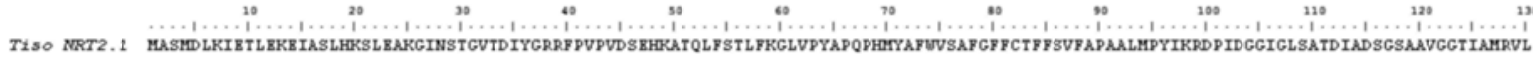
peptide 2 - - 2 -

peptide

peptide 9

peptide 12

peptide 12

peptide 19

-

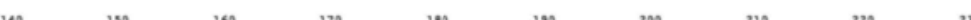

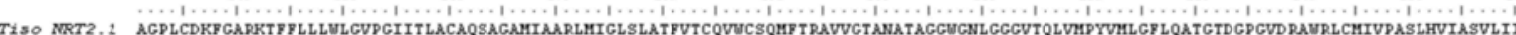
peptide 19

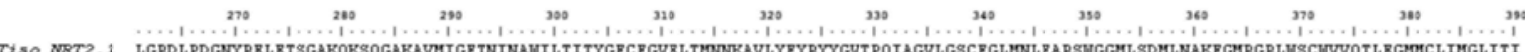
peptide 4 - 4 -

peptide 14

$400 \quad 410 \quad 420 \quad 40$

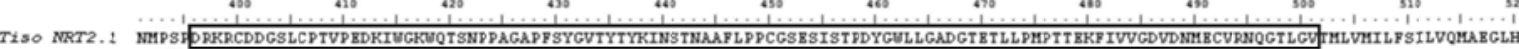

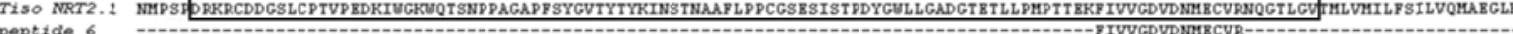
peptide 7

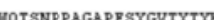

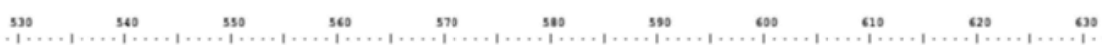

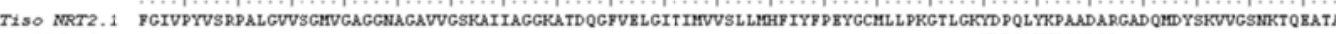

peptide 1 - 10 tide 5 - 